\title{
Don't Know What You Got:
}

A Bayesian Hierarchical Model of Neuroticism and

Nonresponse

Jonathan D. Klingler, Gary E. Hollibaugh, Jr., Adam J. Ramey 


\title{
Don't Know What You Got: A Bayesian Hierarchical Model of Neuroticism and Nonresponse*
}

\author{
Jonathan D. Klingler ${ }^{\dagger}$ \\ Gary E. Hollibaugh, Jr. ${ }^{\ddagger}$ \\ Adam J. Ramey
}

July 7, 2015

\begin{abstract}
Individuals who are more sensitive to punishment from error are more likely to provide nonresponses in surveys. We argue Neurotics' sensitivity to punishment leads them to avoid gathering costly information and forming/reporting opinions about stimuli. Using data from the 2014 Cooperative Congressional Election Study, we show Neuroticism is strongly and positively associated with NA/DK responses when placing politicians on a 7point ideological scale. We then introduce to political science a Bayesian hierarchical model that allows nonresponse to be generated by both a lack of information as well as disincentives for response. Using this model, we show that the NA/DK responses in these data are likely due to inhibited information collection - as opposed to indecision from error avoidance-by Neurotics.
\end{abstract}

*Author order was determined by a spirited game of Diplomacy. All authors contributed equally to the paper. We thank Megan Remmel for feedback and comments. Support through ANR-Labex IAST and the University of Notre Dame Center for Research Computing is gratefully acknowledged.

${ }^{\dagger}$ Corresponding author. Postdoctoral Fellow, Institute for Advanced Study in Toulouse, 21 alleé de Brienne, Toulouse 31000, France. Email: jonathan.klingler@iast.fr

${ }^{\ddagger}$ Assistant Professor, Department of Political Science, University of Notre Dame, Notre Dame, IN 46556. Email: gholliba@nd.edu

${ }^{\$}$ Assistant Professor of Politics, New York University Abu Dhabi, PO Box 129188, Abu Dhabi, United Arab Emirates. Email: adam.ramey@nyu.edu 


\section{Introduction}

Individuals may fail to respond to political questions for many reasons. One reason may be the influence of an individuals' personality traits. ${ }^{1}$ Personality traits are persistent individual differences, and personality psychologists have developed trait structures to capture underlying structure in those that have been identified. The five factor model of personality traits has achieved a high degree of support from psychologists, and political scientists have been incorporating the Big Five personality traits identified by this model into the study of political behavior and institutions (Dietrich et al. 2012, Gerber et al. 2010, Gerber et al. 2011a, Mondak \& Halperin 2008, Mondak et al. 2010). Neuroticism is associated with instability and variability, suggesting it is of particular importance for information processing (Flehmig et al. 2007, Mondak et al. 2010, Robinson \& Tamir 2005), and it has been associated with lower levels of political knowledge (Gerber et al. 2011b). However, there are a number of mechanisms by which it may express itself through nonresponse on items requiring political knowledge-namely, inhibited data collection and indecisiveness from lower expected utilities of response. Neurotics may inhibit their exposure to contentious political information, or they may be less likely to form opinions due to "mental noise" or, as we argue, error sensitivity (Gerber et al. 2011b, Mondak \& Halperin 2008, Robinson \& Tamir 2005). However, little work has been done to understand how Neuroticism leads individuals to be less likely to respond to political questions, a question we investigate here. ${ }^{2}$

However, doing so requires statistical methods that model the underlying nonresponse decision, as both psychological processes (inhibition and indecision) result in observationally equivalent NA/DK responses, but treating such responses identically has the potential to affect inferences due to underlying group-level heterogeneity. This is endemic to survey research, as many

\footnotetext{
${ }^{1}$ Evidence suggests personality traits are stable and causally prior to attitudes and behaviors, which draws us to these particular variables even though we acknowledge that there are many other psychological variables that may be important (Fraley \& Roberts 2005, McCrae 1994, McCrae \& Costa 1996, Roberts \& DelVecchio 2000).

${ }^{2}$ One notable exception is the work of Jessee (2015) and Ramey, Klingler \& Hollibaugh (2015a), who argued personality traits are unrelated to why individuals choose "don't know" responses on surveys.
} 
surveys give individuals the opportunity to skip questions (NA) or elicit "don't know" (DK) responses. Though traditional practice often involves deleting these observations, doing so can lead to biased inferences. Fortunately, Bradlow \& Zaslavsky (1999) provide an approach that models missingness using a hierarchical, multiple latent variable approach. It considers individuals' responses to ordinal indicators as a product of three variables: saliency, opinion, and decisiveness.

Remarkably, this approach mirrors our model of decisionmaking as a function of Neuroticism. We expand on this approach and marry it with the insights of the Aldrich \& McKelvey (1977) approach to modeling ideological placements of elites by voters. This hybrid model allows us to use surveys with missing data to estimate the ideological placements of elites in a common space, and to examine the underlying psychological processes that result in NA/DK responses, which would not be possible with more conventional methods of dealing with missingness. ${ }^{3}$

The rest of the paper proceeds as follows. We first discuss the literature on missingness and multiple imputation. We then discuss the five factor model of personality, focusing on Neuroticism, and review existing literature on its connection with political information. We then expand upon the core cognitive constraint framework proposed by Ramey, Klingler \& Hollibaugh (2015b), and articulate two mechanisms-inhibition and indecision-for this trait that this framework implies. ${ }^{4}$ We then introduce and discuss our new Bayesian hierarchical model. Subsequently, we investigate the relationship between Neuroticism and NA/DK responses. We predict NA/DK responses as a function of both the ability of individuals to collect adequate information to form an opinion on an item (salience) as well as their sensitivity to potential error disutility from reporting clear opinions (decisiveness). The results suggest that NA/DK responses are primarily a feature of Neuroticism's inhibited information gathering as opposed to indecisiveness from error sensitivity. We then discuss the implications of our results for the study of political information as well as the characterization of personality traits for modeling

\footnotetext{
${ }^{3}$ Even modifications of the Aldrich-McKelvey method that allow for missing data (e.g., Hare et al. 2014) assume the missingness is random, which we argue is an untenable assumption.

${ }^{4}$ For an alternative perspective, see Hall (2015).
} 
purposes.

\section{Missing Data}

Missing data have long drawn the ire of social science researchers. In the case of surveys, item nonresponse can cause serious problems for multivariate analysis. Moreover, traditional remedies like listwise deletion, pairwise deletion, mean-insertion, or dummy variable adjustment have been shown to cause serious bias in estimates and/or inferences (King et al. 2001, Allison 2009). As a result, a large literature (e.g., Berinsky 1999, Brehm 1993, Gelman, King \& Liu 1998, Heckman 1976, King et al. 2001, Rubin 1976, Rubin 1977, Rubin 1987) has emerged to model missingness in ways that minimize the inference bias traditional remedies might induce.

This literature can be divided into two loosely-defined classes. The first is that of multiple imputation models (e.g., Gelman, King \& Liu 1998, Rubin 1976, Rubin 1977, Rubin 1987). This paradigm seeks to "impute" the missing values by using other observed information in the data. The method has become popular, as it is easy to implement and available in most standard statistical packages. Though some difficulty may arise when variables are nominal or ordinal, as is the case in surveys, imputation is about as close as one can get to a one-size-fits-all methodology.

However, this approach has limitations, two of which are of particular interest here. First, the missingness must obey the so-called missing at random assumption. Following King et al. (2001), data satisfy MAR if missingness can be modeled as a function of observed data. However, if the missing observations cannot be predicted from observed covariates, MAR is not satisfied and multiple imputation is no longer an option (Weisberg 2009). A second issue is that individuals who do not choose a response or elicit "don't know" may be actually making a choice in the same sense as the other categories given to them. If this is true, King and his co-authors concede that cases “...when 'no opinion' means that the respondent really has no opinion rather than prefers not to share information with the interviewer, should be treated seriously and modeled 
directly...” (King et al. 2001, p. 59).

The other class is deemed by King et al. (2001) as "application specific" (e.g., Bartels 1999, Berinsky 1999, Brehm 1993, Heckman 1976, Jessee 2015), and generally requires modeling of the missingness mechanism, which can be difficult and varies across applications. For example, two such approaches (Berinsky 1999, Heckman 1976) consider data in terms of the selection model, where those choosing NA/DK select themselves out of the sample. This approach yields useful results, but it has limitations; these models require exclusion restrictions to ensure identification, and they restrict missingness to result from only one choice. However, it is also plausible to think missingness results from several different factors, including insufficient information to form and report opinions, disincentives for response, or indifference due to uncertainty.

Relatedly, there is a rich literature on uncertainty and candidate evaluation that is generally more concerned with examination of uncertainty manifesting itself as response variance than nonresponse (e.g. Alvarez 1999, Alvarez \& Brehm 2002, Alvarez \& Franklin 1994, Glasgow \& Alvarez 2000, Zaller \& Feldman 1992). However, Bartels (1986) considers nonresponse to be a result of uncertainty, and Alvarez \& Franklin (1994) note that "it is natural to treat these 'don't know' respondents as more uncertain than those who place the [stimulus], but then say they are not very certain of the location" (680). Since missingness may result from uncertainty, we find it plausible that it may arise from either insufficient information to form and report an opinion, from low expected utilities of response among those who have opinions, or both. ${ }^{5}$ We believe that focusing on personality traits-in particular, Neuroticism-and modeling the decisionmaking process can help us understand and uncover the different reasons why respondents elicit NA/DK responses. ${ }^{6}$

\footnotetext{
${ }^{5}$ We assume individuals are sensitive to error, such that uninformative beliefs and subsequent guessing might lead nonresponse to be optimal (Holroyd \& Coles 2002). Furthermore, among individuals who have uncertain but informative beliefs, the expected utility of response would be a function of the penalties (or rewards) for 'incorrect' (or 'correct') responses and the probability of providing such a response. The probability of incorrect responses would presumably increase with belief variance.

${ }^{6}$ While Jessee (2015) examines the relationship between personality and "don't know" responses, he does not explicitly model the decisionmaking process that leads to such responses, instead preferring to rely on a multinomial
} 


\section{Neuroticism, Inhibition, and Indecision}

The Big Five model of personality proposes five personality traits derived from factor analysis of personality questionnaires as well as descriptive language (Goldberg 1981, John 1990), and this five-trait structure-Openness, Conscientiousness, Extraversion, Agreeableness, and Neuroticism (often reverse-coded as Emotional Stability)-has achieved prominence (Block 1995, Eysenck 1992, John, Naumann \& Soto 2008). These traits have been used to predict life outcomes ranging from romantic fulfillment to mortality, with predictive power comparable to socioeconomic status and cognitive ability (Roberts et al. 2007). Neuroticism in particular is associated with anxiety, depression, impulsiveness and vulnerability to stress (Almlund et al. 2011). Related traits include external locus of control, high irritability and a sense of vulnerability to external conditions (John, Robins \& Pervin 2008). Neurotics tend to have low self-esteem and are unstable, withdrawn, easily angered, and difficult to motivate.

There are few clear connections between Neuroticism and political phenomena, though one that has received attention is an association with ideological extremism (Soldz \& Vaillant 1999). A second line of inquiry stems from the idea that Neurotics may have more uncertainty about the attitudes they do have (Mondak et al. 2010). Others have examined the relationship between Neuroticism and political information. Mondak \& Halperin (2008) hypothesized Neurotics' instability would lead them to be more opinionated (in contrast with emotionally stable individuals who would remain calm and silent) and found that Neurotics have less political knowledge, and lower levels of opinionation, but not necessarily less political interest. Gerber et al. (2011b) posited political contentiousness would prevent Neurotics from becoming interested and knowledgeable about politics, a contention supported by the data. However, we have not yet been able to distinguish between insufficient political knowledge about political stimuli (measured via nonresponse) arising from either inhibited information collection or from refusal to reveal

probit item response model. However, this approach, while useful, is inapplicable when the decisionmaking process is hierarchical and NA/DK responses may arise from different processes, which is what we argue here. 
opinions, through Neuroticism has been connected to both mechanisms. We spend the rest of this section articulating how Neuroticism's neurological roots should lead individuals to perceive greater penalties for error (and thus be more likely to refuse to form and reveal a clear opinion) and less likely to collect information.

The association between Neuroticism and error sensitivity has been linked to serotonin in the brain (Gray \& McNaughton 2003), with a broader theory arguing that Neuroticism is a biochemically induced fixation on punishment (DeYoung \& Gray 2009, Gray \& McNaughton 2003). In the lab, Neurotics are prone to behavioral inhibition through passive avoidance and freezing, presumably due to this fixation on punishment (DeYoung \& Gray 2009). If Neurotics are fixated on error and punishment, absent some shock, the best way to avoid punishment and stress would be to withdraw and maintain the status quo. Whether through sensitivity to error, stress avoidance, or a tendency to negative self-evaluation, Neuroticism can be modeled as a sensitivity to and fixation on prospective punishment, as proposed by Ramey, Klingler \& Hollibaugh (2015b).

Punishment in this context refers to losses relative to a neutral reference point, and modeling utility in such a manner is similar to the approach taken by prospect theory (Depue \& Collins 1999, Derryberry \& Reed 1994, Kahneman \& Tversky 1979, Tversky \& Kahneman 1992). Fortunately, the process by which individuals choose to form an opinion and report such an opinion in a survey is a decision-theoretic one, meaning that we can consider the decision by an individual to form a clear opinion on the ideological position of a political actor. In line with the relative utility structure suggested by the neuropsychology literature on Neuroticism, we assume there is a status quo baseline with zero utility. It is trivial to state that any losses in comparison with the status quo are thus negative utilities, and any gains are accordingly positive utilities.

We assume individuals, when presented with a stimulus, must choose between forming and reporting a clear opinion, or not forming and reporting an opinion. In the present context, we use the term formation to refer to both the decision to form an opinion and report that opinion for public evaluation. If no opinion is formed, the status quo is maintained and the individual 
receives neither punishment nor reward. If an opinion is formed, the individual forms the correct one with probability $p \in(0,1)$ and receives a reward, $R$, or the incorrect one with probability $1-p$ and receives a punishment $L$. We assume the punishment is a negative emotional state which arises from experiencing error, and the reward consists of the positive feelings from being correct, as well as any other gains that may result from having accurate information.

Suppose there is a two dimensional type space for the sensitivity to reward and punishment. We assume the sensitivity of an individual to punishment is $x \in[1, \infty)$ and the sensitivity to reward is $y \in[1, \infty)$. Thus, the punishment, $L$, is weighted by $x$, and the reward, $R$, is weighted by $y$. As a result, we have the following utilities for opinion formation and non-formation:

$$
\begin{aligned}
& U_{N}=0 \\
& U_{F}=p R y-(1-p) L x .
\end{aligned}
$$

We define $m$ to be $\frac{R}{L}$, or the ratio of the magnitude of the reward to the magnitude of the punishment. If we identify the conditions under which it is optimal to not form an opinion, and substitute in $m$ appropriately, we see non-formation is weakly optimal when

$$
x \geq\left(\frac{p}{1-p}\right) m y .
$$

Thus, as the importance of punishment increases, non-formation is more likely to be optimal.

Now, consider an extension where the player may pay a cost $c \in[0, \omega(R y+L x)]$ to collect additional information and increase the probability of a correct opinion from $p$ to $p+\omega$, where $\omega \in(0,1-p]^{7,8}$ The costs of information acquisition aside, the utility of non-formation is unaffected by $p$, while the utility of formation increases. However, we assume individuals will look at the potential benefit of paying the cost and will only do so if it weakly increases their expected

\footnotetext{
${ }^{7}$ For tractability, assume both $c$ and $\omega$ are exogenously determined. However, the substantive results are similar if the individual is allowed to pay varying costs $c$ for varying amounts of information.

${ }^{8}$ The upper bound on $c$ ensures the cost is sufficiently reasonable relative to $\omega$.
} 
utility. Therefore, the ability to pay for information acquisition results in three cases. In the first case, where $x<\left(\frac{p}{1-p}\right) m y$, then opinion formation is always optimal, and the individual is sufficiently insensitive to punishment that there is no need to pay for more information before doing so. However, since doing so increases the probability of being correct, and therefore increases the potential rewards relative to the potential punishments, the individual will pay the cost. In the second case, where $x \in\left[\left(\frac{p}{1-p}\right) m y,\left(\frac{p+\omega}{1-p-\omega}\right) m y-\frac{c}{L(1-p-\omega)}\right]$, then opinion formation is optimal, conditional on the individual paying for more information before doing so, as he or she is sufficiently sensitive to punishment (but not so much that opinion formation is never optimal). Finally, in the third case, where $x>\max \left\{\left(\frac{p}{1-p}\right) m y,\left(\frac{p+\omega}{1-p-\omega}\right) m y-\frac{c}{L(1-p-\omega)}\right\}$, then opinion formation is never optimal, because the individual is so sensitive to punishment that not even the additional information that could be purchased will be sufficient (at least at the specified cost). Additionally, since there are limits to the information that may be gathered, increasing $x$, ceteris paribus, will weakly increase the probability no opinion is formed and gathering no information becomes more optimal. Figure 1 presents an example of how shifts in the relative sensitivities to reward and punishment affect the opinion formation and information acquisition decisions. ${ }^{9}$

We assume personality measures for the trait of Neuroticism capture its core cognitive constraint, which is a sensitivity to prospective punishment. Accordingly, Neuroticism is associated with sensitivity to punishment, parameterized as $x$ in the above model. In the empirical model we present below, the utility of response relative to nonresponse is described as decisiveness. ${ }^{10}$ As increases in $x$ are associated with an increased likelihood of choosing not to form an opinion, we obtain the following hypothesis for Neuroticism:

\section{Hypothesis 1 More Neurotic individuals should be less be decisive.}

Next, collecting information on a particular stimulus can be described as finding that stimulus

\footnotetext{
${ }^{9}$ Figure 1 was created using $R=3, L=3, p=0.5, \omega=0.2, x \in[1,10], y \in[1,10]$, and $c=1$.

${ }^{10}$ This terminology used by Bradlow \& Zaslavsky (1999) in the discussion of the hierarchical model used here. This terminology is limited to this model and not the broader concept of decisiveness in the public opinion literature.
} 


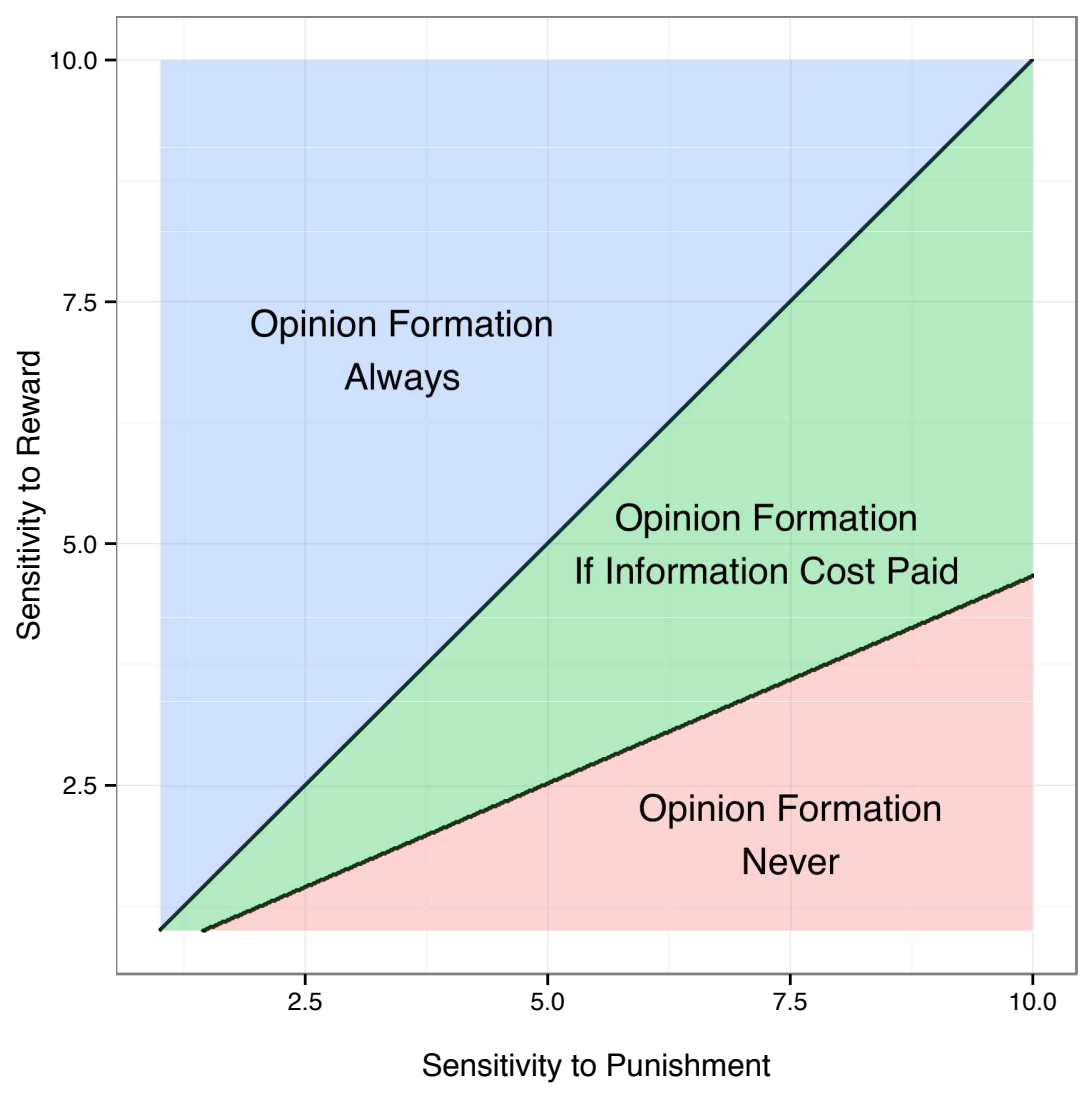

Figure 1: Opinion Formation as a Function of Sensitivities to Reward and Punishment to be salient. In the decision described above, as $x$ increases, it is more likely it will be suboptimal for an individual to collect information on a stimulus. This generates a second hypothesis:

Hypothesis 2 More Neurotic individuals should find the response stimuli less salient.

As Neurotic individuals collect less information and are less likely to choose to form and report opinions, we expect them to be more likely to not have clear evaluations of stimuli and therefore present NA/DK responses, suggesting the following hypothesis:

Hypothesis 3 More Neurotic individuals should provide more NA/DK responses.

Finally, as Neurotics will collect less information, they will be less informed about broad sets of stimuli, including the ideological scale itself, thus generating our final hypothesis: 
Hypothesis 4 More Neurotic individuals should incorrectly perceive the ideological scale.

\section{A Statistical Model of the Decisionmaking Process}

The most common approach to modeling ideological placements of elites by voters was pioneered by Aldrich \& McKelvey (1977). The Aldrich-McKelvey algorithm assumes an arbitrary individual $i$ 's placement of an elite stimulus $j$ on an ordinal ideological scale is given by

$$
y_{i j}=a_{i}+b_{i} x_{j}+\varepsilon_{i j}
$$

where $a_{i}$ and $b_{i}$ are individual distortion parameters and $x_{j}$ are the latent ideological locations of the elite stimuli. ${ }^{11}$ The distortion parameters capture the idea that individuals may perceive the underlying ideological space in different ways. Aldrich \& McKelvey (1977) estimate this model using a Singular Value Decomposition (SVD) and demonstrate it accurately recovers the locations of the stimuli and the levels of information possessed by the survey respondents.

Unfortunately, this procedure cannot handle missing values and removes individuals who fail to place even just one stimulus. Addressing this shortcoming, Hare et al. (2014) develop a Bayesian version that can incorporate missing values. ${ }^{12}$ Their approach assumes missing placements are missing at random and are drawn from the assumed distribution of the placements.

However, this assumption is problematic in general and in particular with respect to Neuroticism. Specifically, we do not believe missing placements are missing at random. Instead, we believe missing placements are influenced by individuals' personality traits-namely, their varying degrees of Neuroticism. If this is the case, then we should actively model the decisionmaking process whereby individuals decide to answer (or not to answer) elite placement questions.

Our approach does just this. We expand upon a model developed in the marketing literature

\footnotetext{
${ }^{11}$ This formulation is simplified from the original paper, but is equivalent with appropriate substitutions.

${ }^{12}$ However, it still requires a minimum number of stimuli are scaled by a given respondent.
} 
by Bradlow \& Zaslavsky (1999), which assumes NA/DK responses are driven by latent psychological processes. We takes this approach and marry it with the core insights of the AldrichMcKelvey algorithm. While our specific interests are in the effects of Neuroticism, the general framework we develop can be applied to any similar decisionmaking setup.

\subsection{The Model}

Let $i=1,2, \ldots, N$ denote the set of respondents to a survey and let $j=1,2, \ldots, J$ denote the a set of stimuli that they are asked to rate on an ordinal scale. For each individual $i, y_{i j}$ is his ordinal response to item $j$. Typically, these sorts of items involve five- or seven-point scales. If $i$ skipped the item, his response is coded as either NA or DK. In most analyses of these data, ordered probit or logit are employed, with the probabilities of the various $y_{i j} \mathrm{~s}$ modeled as functions of covariates $X$ and cutpoints $c_{q}$. Estimation is either achieved by maximizing a likelihood function or, with assignment of priors, a sampling from posterior distributions.

This can be interpreted as a generalization of the ordered probit, with the main departure being the multiple latent variables. In the ordered probit, the $y_{i j} \mathrm{~s}$ are viewed as realizations of an underlying $y_{i j}^{*}$, where the ordinal values are determined by cutpoints on the latent scale. The hierarchical approach views an individual's response as a product of three latent processes: saliency, opinion, and decisiveness. Saliency, given by $\psi_{i j}$, is the first latent factor in the decision-maker's process. If the item is not salient, $\psi_{i j}<0$ and the respondent will elicit a NA/DK response.

If the item is salient, the next stage involves computing $i^{\prime}$ s opinion about the location of $j, \vartheta_{i j}$. Since placing stimuli at extremes of the scale might be systematically different from placing them at the center, respondents whose latent opinion is more extreme are assumed to have definitive opinions. The extremity is defined in terms of cutpoints, $c_{q}$, where $q=1, \ldots, Q-1$ represents the ordinal response category, $c_{0}=-\infty$ and $c_{Q}=\infty$. An opinion $\vartheta_{i j}$ is considered extreme if

$$
\vartheta_{i j} \notin\left[c_{L}, c_{H}\right]
$$


Figure 2: The Hierarchical Model

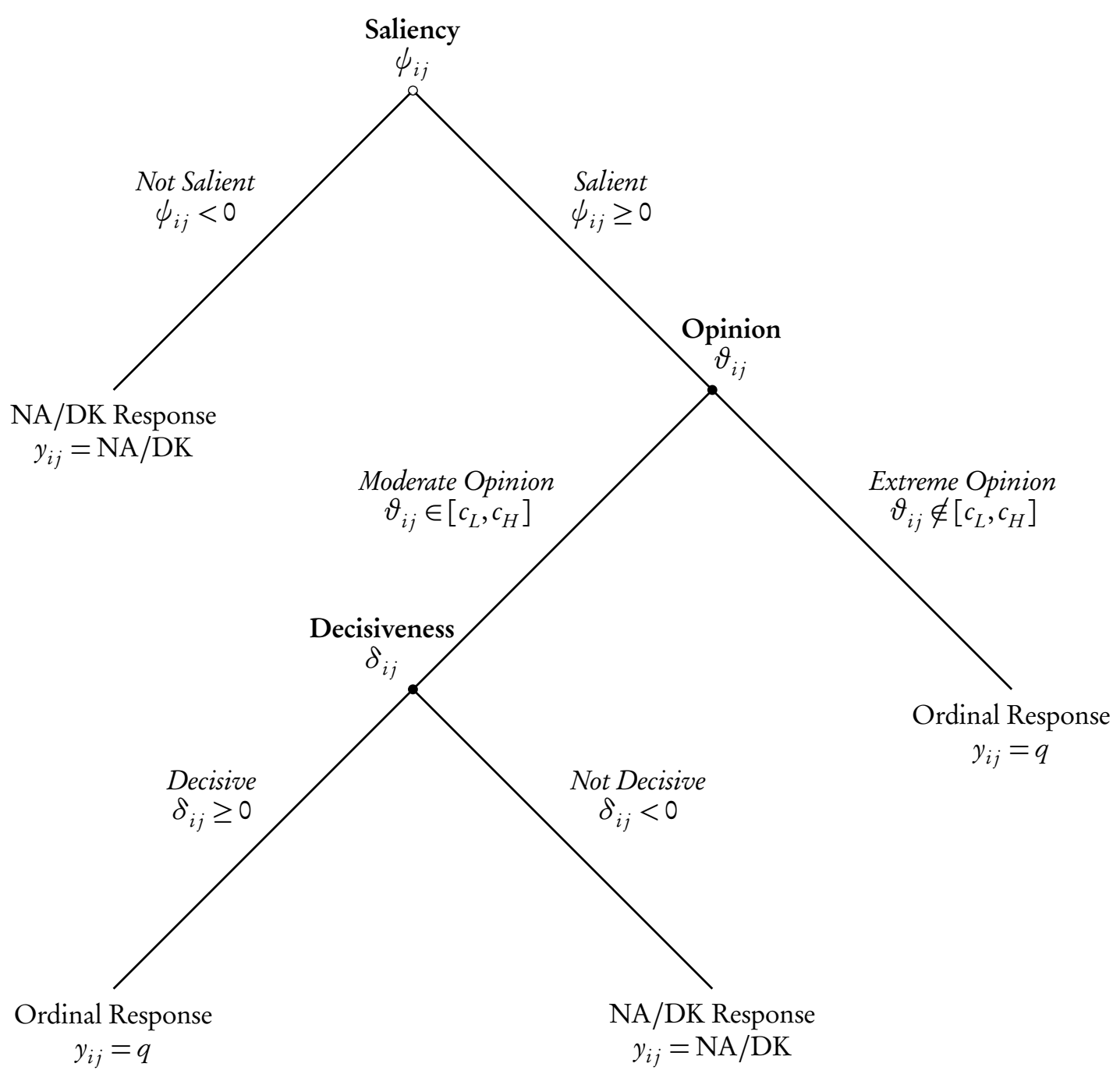

where the cutpoints $c_{L}$ and $c_{H}$ depend on the number of possible ordinal responses given on the particular item. In particular, it is assumed that $c_{L}=c_{q_{L}-1}$ and $c_{H}=c_{q_{H}} \cdot q_{H}$ and $q_{L}$ are typically chosen so that they straddle the cutpoint that corresponds to the center-most category. For example, if the observed data is from a seven-point scale, category 4 is at the center. This makes $q_{L}=3$ and $q_{H}=5$ ideal candidates for $c_{L}=c_{2}$ and $c_{H}=c_{5}$ respectively. ${ }^{13}$

\footnotetext{
${ }^{13}$ Depending on the data, researchers may desire to modify the indifference region bounds accordingly.
} 
Should $i$ have a $\vartheta_{i j}$ that satisfies the above condition, we assume that he will elicit an ordinal response and not NA/DK. However, if $\vartheta_{i j} \in\left[c_{L}, c_{H}\right]$, we say that $i$ is in the region of indifference. This, in turn, leads to the last stage in the decision tree. We can imagine that a latent opinion in this range might lead to one of two observed behaviors. If the individual is decisive, then he would be more inclined to elicit an ordinal response than if he were indecisive. This notion is formalized in the third latent variable $\delta_{i j}$, where $\delta_{i j} \geq 0$ implies $i$ 's decisiveness on the item and hence, an ordinal response will be given. If he is not decisive, $\delta_{i j}<0$ and the NA/DK response is given. The entire process is depicted in Figure 2.

This model provides a rich description of behavior. For example, the NA/DK response can be observed if the respondent has a high expected value of nonresponse (indecisiveness) or if the respondent lacks adequate information with which to form an opinion (salience). These are different kinds of NAs and are modeled as such. Additionally, if there are no NAs, this model reduces to a simple ordered probit; this model is therefore always preferred, as it picks up effects that the ordered probit would miss, but still produces the same results when NAs are absent.

\subsection{Hierarchy I: Distribution of $y \mid \phi_{1}, \phi_{2}$}

It is assumed the three latent variables, $\psi_{i j}, \vartheta_{i j}$, and $\delta_{i j}$ are distributed normally with variance 1. Saliency, $\psi_{i j}$, is assumed have a mean $\mu_{i j}^{\psi}$ such that

$$
\mu_{i j}^{\psi}=\eta_{i}+X_{i j}^{\psi} \beta^{\psi}
$$

where $\eta_{i}$ is a random intercept allowing individuals to vary in terms of saliency and $X_{i j}^{\psi}$ is a vector of person-item covariates thought to influence saliency. This captures the idea that when certain properties of the stimuli match certain properties of the respondent, the item might then be more 
(or less) salient. For the latent opinion $\vartheta_{i j}$, the mean is given by

$$
\mu_{i j}^{\vartheta}=\alpha_{i}+\gamma_{i} \xi_{j}
$$

where $\xi_{j}$ is the true latent position of stimulus $j$ and $\left(\alpha_{i}, \gamma_{i}\right)$ are individual-specific distortion parameters. This approach deviates from the original Bradlow \& Zaslavsky (1999) model, but is in keeping with the literature in political science that uses the Aldrich \& McKelvey (1977) technique (e.g., Hare et al. 2014, Hollibaugh, Rothenberg \& Rulison 2013). Importantly, unlike the Aldrich-McKelvey approach, we treat ordinal responses as ordinal (and not continuous).

The final latent variable, decisiveness $\delta_{i j}$ has a mean

$$
\mu_{i j}^{\delta}=Z_{i}^{\delta} \beta^{\delta}
$$

and $Z_{i}^{\delta}$ is a vector of covariates affecting decisiveness. These covariates are not indexed by $j$, as decisiveness is assumed to be a property of the individual and not the items.

These latent draws may be summarized as follows:

$$
\begin{aligned}
& \psi_{i j} \sim \mathcal{N}\left(\mu_{i j}^{\psi}, 1\right) \\
& \vartheta_{i j} \sim \mathcal{N}\left(\mu_{i j}^{\vartheta}, 1\right) \\
& \delta_{i j} \sim \mathcal{N}\left(\mu_{i j}^{\delta}, 1\right) .
\end{aligned}
$$

The complete data likelihood is found based on the above definitions of the latent variables. The likelihood function is given by

$$
\mathcal{L}\left(\phi_{1}, \phi_{2} \mid y_{i j}, X, Z\right) \propto \prod_{i=1}^{N} \prod_{j=1}^{J} p_{i j}\left(\phi_{1}, \phi_{2} \mid y_{i j}, X\right)
$$

where the $p_{i j}$ are probabilities associated with the ordinal outcomes. For simplicity, Figure 3 
Figure 3: The Hierarchical Model with Probabilities

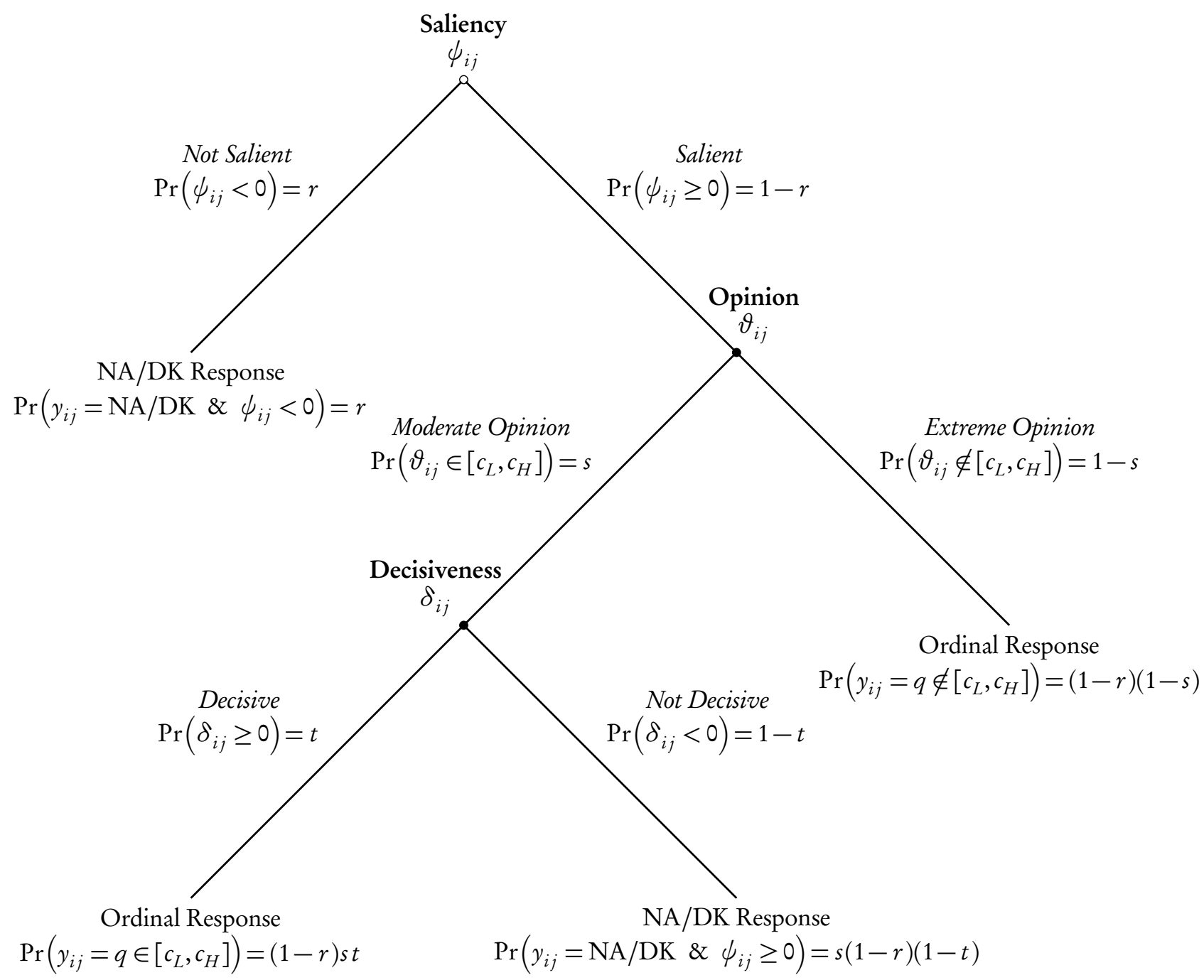

presents a simplified decision tree broken down into three different probabilities: $r, s$, and $t$. To evaluate $p_{i j}$ in these terms, we need to look at the various responses that could be provided on the ordinal items. First, we consider the case where $i$ elicits NA/DK. This could have resulted 
two ways, as is seen in Figure 3. Thus, the probability of observing a NA/DK response is

$$
\begin{aligned}
\operatorname{Pr}\left(y_{i j}=\mathrm{NA} / \mathrm{DK}\right) & =r+s(1-r)(1-t) \\
& =\Phi\left(-\mu_{i j}^{\psi}\right)+\left(\Phi\left(c_{q_{H}}-\mu_{i j}^{\vartheta}\right)-\Phi\left(c_{q_{L}}-\mu_{i j}^{\vartheta}\right)\right)\left(1-\Phi\left(-\mu_{i j}^{\psi}\right)\right) \Phi\left(-\mu_{i j}^{\delta}\right) .
\end{aligned}
$$

Second, we look at non-NA responses that fall outside of the indifference region. The probability of observing a response outside of this region is given by

$$
\begin{aligned}
\operatorname{Pr}\left(y_{i j}=q \notin\left[q_{L}, q_{H}\right]\right) & =(1-r)(1-s) \\
& =\left(1-\Phi\left(-\mu_{i j}^{\psi}\right)\right)\left(\Phi\left(c_{q}-\mu_{i j}^{\vartheta}\right)-\Phi\left(c_{q-1}-\mu_{i j}^{\vartheta}\right)\right) .
\end{aligned}
$$

Finally, there is the probability of observing a non-NA response that is within the indifference region. Examining Figure 3, this is given by

$$
\begin{aligned}
\operatorname{Pr}\left(y_{i j}=q \in\left[q_{L}, q_{H}\right]\right) & =(1-r) s t \\
& =\left(1-\Phi\left(-\mu_{i j}^{\psi}\right)\right)\left(\Phi\left(c_{q}-\mu_{i j}^{\vartheta}\right)-\Phi\left(c_{q-1}-\mu_{i j}^{\vartheta}\right)\right)\left(1-\Phi\left(-\mu_{i j}^{\delta}\right)\right) .
\end{aligned}
$$

Note that in Equation 12, $\Phi\left(c_{q}-\mu_{i j}^{\vartheta}\right)-\Phi\left(c_{q-1}-\mu_{i j}^{\vartheta}\right)$ is denoted as $1-s$, whereas in Equation 13 it is defined as $s$. This is due to $s$ representing an arbitrary choice inside the indifference region, whereas $\Phi\left(c_{q}-\mu_{i j}^{\vartheta}\right)-\Phi\left(c_{q-1}-\mu_{i j}^{\vartheta}\right)$ represents a particular choice $q$ that is assumed to be either outside (Equation 12) or inside (Equation 13) the indifference region. That in mind, we can assemble the pieces indicated in Equations 11 through 13 into a single statement as follows:

$$
p_{i j}\left(y_{i j}\right)=\left\{\begin{array}{cl}
\Phi\left(-\mu_{i j}^{\psi}\right)+\left(\Phi\left(c_{q_{H}}-\mu_{i j}^{\vartheta}\right)-\Phi\left(c_{q_{L}}-\mu_{i j}^{\vartheta}\right)\right)\left(1-\Phi\left(-\mu_{i j}^{\psi}\right)\right) \Phi\left(-\mu_{i j}^{\delta}\right), & \text { if } y_{i j}=\mathrm{NA} / \mathrm{DK} \\
\left(1-\Phi\left(-\mu_{i j}^{\psi}\right)\right)\left(\Phi\left(c_{q}-\mu_{i j}^{\vartheta}\right)-\Phi\left(c_{q-1}-\mu_{i j}^{\vartheta}\right)\right), & \text { if } y_{i j}=q \notin\left[q_{L}, q_{H}\right] \\
\left(1-\Phi\left(-\mu_{i j}^{\psi}\right)\right)\left(\Phi\left(c_{q}-\mu_{i j}^{\vartheta}\right)-\Phi\left(c_{q-1}-\mu_{i j}^{\vartheta}\right)\right)\left(1-\Phi\left(-\mu_{i j}^{\delta}\right)\right), & \text { if } y_{i j}=q \in\left[q_{L}, q_{H}\right] .
\end{array}\right.
$$




\subsection{Hierarchy II: Distribution of $\phi_{1} \mid \phi_{2}$}

The second layer of hierarchy looks at the vector of prior parameters $\phi_{1}=(\eta, \alpha, \gamma, \xi)$. Each of these is normally distributed as follows:

$$
\begin{aligned}
& \eta_{i} \sim \mathcal{N}\left(Z_{i}^{\eta} \beta^{\eta}, \sigma_{\eta}^{2}\right) \\
& \alpha_{i} \sim \mathcal{N}\left(Z_{i}^{\alpha} \beta^{\alpha}, \sigma_{\alpha}^{2}\right) \\
& \gamma_{i} \sim \mathcal{N}\left(Z_{i}^{\gamma} \beta^{\gamma}, \sigma_{\gamma}^{2}\right) \\
& \xi_{j} \sim \mathcal{N}(0,1) .
\end{aligned}
$$

The $Z^{m}$, for $m \in \phi_{1}$, are matrices of covariates assumed to influence saliency and the scale usage parameters. For identification, we place standard Normal priors on the stimuli. In the following application, we assume the matrices of covariates are the same across parameters (i.e., $Z^{m}=Z$ ).

\subsection{Hierarchy III: Distribution of $\phi_{2}$}

The final layer is the vector of hyperparameters for the coefficients, variances, and cutpoints:

$$
\phi_{2}=\left(\beta^{\psi}, \beta^{\delta}, \beta^{\eta}, \beta^{\alpha}, \beta^{\gamma}, \sigma_{\eta}^{2}, \sigma_{\alpha}^{2}, \sigma_{\gamma}^{2}, c\right) .
$$

Each group of coefficients for each latent parameter $m$ are drawn from a Multivariate Normal distribution with mean 0 and covariance $\Sigma$ :

$$
\beta^{m} \sim \mathcal{M V N}(0, \Sigma)
$$

The choice of $\Sigma$ can be as large or as small as necessary. ${ }^{14}$ For the variance of the saliency intercept and the distortion vectors, we employ an uninformative conjugate prior defined on

\footnotetext{
${ }^{14}$ Here, the diagonal elements of $\Sigma$ are chosen to be 25 .
} 
$\mathbb{R}^{++}$. Standard results show this distribution to be the Inverse Gamma. Thus, the prior for $\sigma_{m}^{2}$,

$$
\sigma_{m}^{2} \sim \mathcal{I} \mathcal{G}\left(\frac{\rho}{2}, \frac{1}{2}\right)
$$

and $\rho$ is chosen to be $\frac{1}{2}$.

Last is the vector of cutpoints. All cutpoints are assumed to be drawn uniformly from the last cutpoint to the current cutpoint. More specifically,

$$
c_{q} \mid c_{q-1}, c_{q+1} \sim U\left(c_{q-1}, c_{q+1}\right), q=1,2, \ldots, Q-1,
$$

$c_{0}=-\infty, c_{Q}=\infty$, and, for identification, some $q^{\prime} \in\{1,2, \ldots, Q-1\}, c_{q^{\prime}}=-1.5$.

\subsection{The Full Posterior}

We combine the expressions for the likelihood and priors to form the complete posterior:

$$
\pi\left(\phi_{1}, \phi_{2} \mid y, X\right) \propto \mathcal{L}\left(y \mid \phi_{1}, \phi_{2}, X\right) p\left(\phi_{1} \mid \phi_{2}, y, X\right) p\left(\phi_{2}\right) .
$$

As is the case with all hierarchical models, there is a large number of parameters to estimate; we are required to estimate a minimum of $3 N+J+Q-3$ parameters (not including the $\beta$ s or $\sigma^{2}$ s). Fortunately, Bayesian methods are well-suited for these sorts of models. We use Plummer's (2003) JAGS software to sample from the full posterior. The model converges relatively quickly, with the results relatively consistent after approximately 5,000 iterations of the Gibbs sampler.

\section{Predicting Nonresponse with Personality}

To examine the relationships between Neuroticism and responses to ideological placement questions as well as the underlying decisionmaking process, we rely on data from the 2014 Cooperative 
Congressional Election Study (CCES). Within this survey, we asked 1,000 respondents to place themselves and nine political figures on a seven-point ideological scale. These figures include President Barack Obama, Hillary Clinton, Jeb Bush, Rand Paul, Ted Cruz, the Democratic and Republican Parties, the Tea Party, and the Supreme Court. We also asked each respondent to take the Ten-Item Personality Inventory ("TIPI") as a way of estimating their Big Five traits on a 1-7 scale, which we then normalized to a 0-1 scale (Gosling, Rentfrow \& Swann 2003). While the TIPI is shorter than standard instruments, it is well-suited to tasks like the CCES, where time is limited, and results from the TIPI tend to be highly correlated with the results one would get from longer and larger batteries of questions (Ehrhart et al. 2009, Gosling, Rentfrow \& Swann 2003).

We first estimate a series of binomial probit models where the dependent variable is the number of NA/DK responses elicited when respondents were asked about the nine figures. In addition to the Big Five, we include as independent variables respondents' age, gender, income, and education, indicator variables for whether they identified as Black, Hispanic, or some other race, a variable (High News Interest) that equals one if the respondent indicated that he or she "follow $[\mathrm{s}]$ what's going on in government and public affairs" most of the time and zero otherwise, and an additional variable (Unknown Nerws Interest) that equals one if the respondent indicated he or she did not know how often they followed current events, and zero otherwise, as these concepts have been shown to be important determinants of ideological uncertainty (e.g., Alvarez \& Franklin 1994, Bartels 1986, Delli Carpini \& Keeter 1996, Jackson 1993). Results are in Table 1.

Across all models, Neuroticism is positively associated with higher proportions of NA/DK responses. Figure 4 illustrates how the predicted proportion of NA/DK responses increases as Neuroticism increases. ${ }^{15}$ As can be seen, the predicted proportion of NA/DK responses increases from about 0.318 (when Neuroticism is set to two standard deviations below its mean) to about 0.435 (when Neuroticism is set to two standard deviations above its mean).

\footnotetext{
${ }^{15}$ In Figure 4, the estimates from Model 5 from Table 1 were used, as it had the lowest BIC of those models estimated. All continuous [categorical] variables were set to their means [modes].
} 
Table 1: Binomial Regression Models of the Number of NA/DK Responses

\begin{tabular}{|c|c|c|c|c|c|c|}
\hline & Model 1 & Model 2 & Model 3 & Model 4 & Model 5 & Model 6 \\
\hline Neuroticism & $\begin{array}{c}0.845^{* * *} \\
(0.090)\end{array}$ & $\begin{array}{c}0.459^{* * *} \\
(0.095)\end{array}$ & $\begin{array}{c}0.385^{* * *} \\
(0.098)\end{array}$ & $\begin{array}{c}0.400^{* * *} \\
(0.102)\end{array}$ & $\begin{array}{c}0.348^{* * *} \\
(0.103)\end{array}$ & $\begin{array}{c}0.330^{* * * *} \\
(0.103)\end{array}$ \\
\hline Conscientiousness & $\begin{array}{c}-0.295^{\text {**** }} \\
(0.096)\end{array}$ & $\begin{array}{c}-0.293^{* * * *} \\
(0.102)\end{array}$ & $\begin{array}{l}-0.069 \\
(0.106)\end{array}$ & $\begin{array}{c}0.060 \\
(0.113)\end{array}$ & $\begin{array}{c}0.069 \\
(0.113)\end{array}$ & $\begin{array}{c}0.032 \\
(0.114)\end{array}$ \\
\hline Agreeableness & $\begin{array}{l}0.591^{* * * *} \\
(0.105)\end{array}$ & $\begin{array}{c}0.496^{* * * *} \\
(0.115)\end{array}$ & $\begin{array}{l}0.244^{* *} \\
(0.119)\end{array}$ & $\begin{array}{c}0.391 * * * \\
(0.125)\end{array}$ & $\begin{array}{l}0.403^{* * * *} \\
(0.126)\end{array}$ & $\begin{array}{c}0.442 * * * \\
(0.127)\end{array}$ \\
\hline Extraversion & $\begin{array}{c}0.049 \\
(0.079)\end{array}$ & $\begin{array}{c}0.106 \\
(0.082)\end{array}$ & $\begin{array}{c}0.075 \\
(0.086)\end{array}$ & $\begin{array}{l}0.201^{* * *} \\
(0.089)\end{array}$ & $\begin{array}{c}0.273^{* * * *} \\
(0.091)\end{array}$ & $\begin{array}{c}0.261^{* * * *} \\
(0.092)\end{array}$ \\
\hline Openness & $\begin{array}{c}-0.505^{* * * *} \\
(0.100)\end{array}$ & $\begin{array}{c}-0.636^{* * * *} \\
(0.105)\end{array}$ & $\begin{array}{c}-0.356^{* * * *} \\
(0.110)\end{array}$ & $\begin{array}{c}-0.262^{* *} \\
(0.114)\end{array}$ & $\begin{array}{c}-0.314^{* * *} \\
(0.115)\end{array}$ & $\begin{array}{c}-0.318^{* * *} \\
(0.117)\end{array}$ \\
\hline Female & & $\begin{array}{c}0.496^{* * * *} \\
(0.040)\end{array}$ & $\begin{array}{c}0.461^{* * * *} \\
(0.041)\end{array}$ & $\begin{array}{c}0.326 * * * \\
(0.043)\end{array}$ & $\begin{array}{c}0.317^{* * * *} \\
(0.043)\end{array}$ & $\begin{array}{l}0.328^{* * * *} \\
(0.044)\end{array}$ \\
\hline Age & & $\begin{array}{c}-0.015^{* * *} \\
(0.007)\end{array}$ & $\begin{array}{c}-0.020^{* * * * *} \\
(0.007)\end{array}$ & $\begin{array}{c}-0.024^{* * * *} \\
(0.007)\end{array}$ & $\begin{array}{c}-0.019 * * * \\
(0.007)\end{array}$ & $\begin{array}{c}-0.014^{*} \\
(0.008)\end{array}$ \\
\hline $\mathrm{Age}^{2} / 100$ & & $\begin{array}{c}0.000 \\
(0.007)\end{array}$ & $\begin{array}{c}0.003 \\
(0.007)\end{array}$ & $\begin{array}{l}0.015^{* *} \\
(0.007)\end{array}$ & $\begin{array}{c}0.009 \\
(0.007)\end{array}$ & $\begin{array}{c}0.001 \\
(0.008)\end{array}$ \\
\hline Black & & $\begin{array}{c}0.072 \\
(0.060)\end{array}$ & $\begin{array}{c}0.073 \\
(0.062)\end{array}$ & $\begin{array}{l}-0.061 \\
(0.065)\end{array}$ & $\begin{array}{c}-0.118^{*} \\
(0.066)\end{array}$ & $\begin{array}{c}-0.127^{*} \\
(0.066)\end{array}$ \\
\hline Hispanic & & $\begin{array}{c}0.362^{* * *} \\
(0.064)\end{array}$ & $\begin{array}{c}0.344^{* * *} \\
(0.066)\end{array}$ & $\begin{array}{c}0.183^{* * *} \\
(0.068)\end{array}$ & $\begin{array}{l}0.159^{\text {*** }} \\
(0.069)\end{array}$ & $\begin{array}{l}0.149^{* *} \\
(0.069)\end{array}$ \\
\hline Other Race & & $\begin{array}{l}0.130^{*} \\
(0.070)\end{array}$ & $\begin{array}{l}0.169^{* * *} \\
(0.071)\end{array}$ & $\begin{array}{c}0.213^{* * *} \\
(0.076)\end{array}$ & $\begin{array}{l}0.195^{* * *} \\
(0.076)\end{array}$ & $\begin{array}{l}0.158^{* *} \\
(0.077)\end{array}$ \\
\hline Education $(1=$ No HS; 6 = Postgrad $)$ & & & $\begin{array}{c}-0.252^{* * *} \\
(0.014)\end{array}$ & $\begin{array}{c}-0.185^{* * *} \\
(0.015)\end{array}$ & $\begin{array}{c}-0.154^{* * *} \\
(0.015)\end{array}$ & $\begin{array}{c}-0.149^{* * * *} \\
(0.015)\end{array}$ \\
\hline High News Interest & & & & $\begin{array}{l}-0.800^{* * * *} \\
(0.048)\end{array}$ & $\begin{array}{l}-0.791^{* * * *} \\
(0.048)\end{array}$ & $\begin{array}{l}-0.800^{* * * *} \\
(0.049)\end{array}$ \\
\hline Unknown News Interest & & & & $\begin{array}{l}1.053^{* * *} \\
(0.101)\end{array}$ & $\begin{array}{l}1.039^{* * * *} \\
(0.101)\end{array}$ & $\begin{array}{l}1.066^{* * *} \\
(0.103)\end{array}$ \\
\hline Income $(1=<10 \mathrm{k} ; 12=>150 \mathrm{k} ; 13=$ Refused $)$ & & & & & $\begin{array}{c}-0.052^{* * *} \\
(0.008)\end{array}$ & $\begin{array}{l}-0.054^{* * *} \\
(0.008)\end{array}$ \\
\hline Income Refused & & & & & $\begin{array}{l}0.360^{* * *} \\
(0.088)\end{array}$ & $\begin{array}{l}0.390 * * * \\
(0.089)\end{array}$ \\
\hline Employed Full-Time & & & & & & $\begin{array}{l}-0.022 \\
(0.053)\end{array}$ \\
\hline Employed Part-Time & & & & & & $\begin{array}{l}-0.215^{* * * *} \\
(0.070)\end{array}$ \\
\hline Unemployed & & & & & & $\begin{array}{l}0.076 \\
(0.082)\end{array}$ \\
\hline Retired & & & & & & $\begin{array}{c}0.123 \\
(0.078)\end{array}$ \\
\hline Constant & $\begin{array}{l}-1.051^{* * *} \\
(0.123)\end{array}$ & $\begin{array}{l}-0.411^{* *} \\
(0.201)\end{array}$ & $\begin{array}{l}0.512^{* *} \\
(0.210)\end{array}$ & $\begin{array}{c}0.181 \\
(0.220)\end{array}$ & $\begin{array}{c}0.284 \\
(0.222) \\
\end{array}$ & $\begin{array}{l}0.231 \\
(0.227) \\
\end{array}$ \\
\hline$\overline{\mathrm{AIC}}$ & 4778.624 & 4318.770 & 3962.678 & 3519.371 & 3474.323 & 3463.090 \\
\hline Log Likelihood & -2383.312 & -2147.385 & -1968.339 & -1744.685 & -1720.161 & -1710.545 \\
\hline Num. obs. & 817 & 817 & 817 & 817 & 817 & 817 \\
\hline
\end{tabular}

We next utilize Aldrich-McKelvey estimation to recover the underlying ideological space. Though this method does not allow one to include NA/DK responses, one benefit is that it provides estimates of respondents' political information, based on the correlation of the "true" 


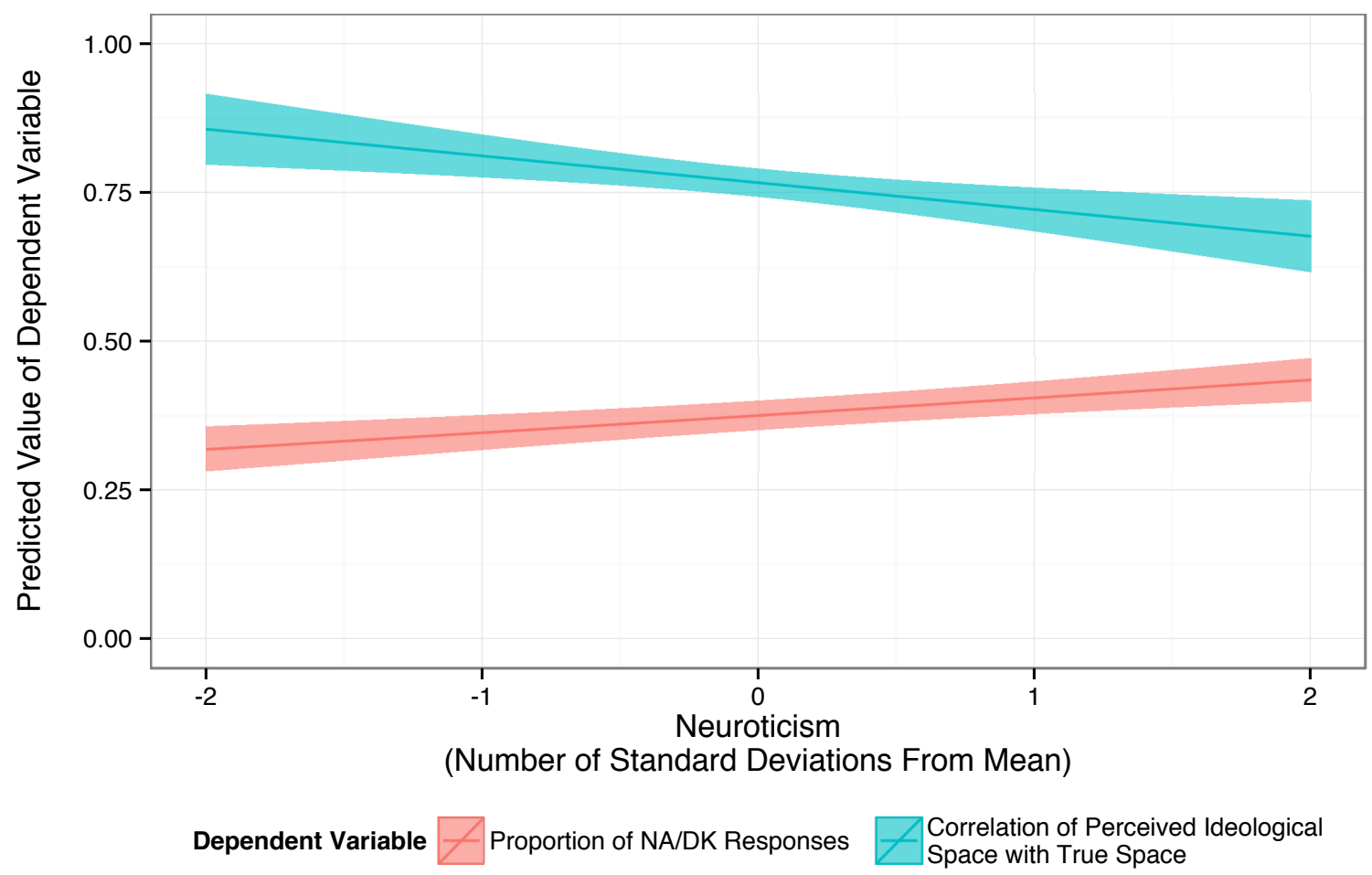

Figure 4: Predicted Results from Tables 1 and 2.

ideological space with how they perceive it. ${ }^{16}$ Higher values indicate respondents' perceptions of the ideological world correlate highly with reality. Table 2 presents the results of a series of Tobit models where the dependent variable is the respondents' estimated level of political information and the independent variables are those used in Table $1 .{ }^{17}$

Across all models, higher levels of Neuroticism are correlated with lower correlations between the "true" ideological space and respondents' perceptions. Figure 4 illustrates how the predicted correlation decreases as Neuroticism increases. ${ }^{18}$ As can be seen, the predicted correla-

\footnotetext{
${ }^{16}$ Hare et al.'s (2014) Bayesian version of the Aldrich-McKelvey algorithm allows for missing values, but relies on the MAR assumption. Additionally, Poole's (1998) "Black Box" method allows one to include NA/DK responses, and the recovered placements are substantively identical to those recovered from the Aldrich-McKelvey method.

${ }^{17} \mathrm{~A}$ Tobit model is used because the dependent variable lies in the $[-1,1]$ interval by construction; substantively identical results are found if a zero-one inflated beta regression model-with the dependent variable rescaled to lie within the $[0,1]$ interval-is used. Though the (rescaled) beta model is arguably more appropriate due to the Tobit's censoring assumptions, the Tobit model results are presented, due to better interpretability.

${ }^{18}$ In the Tobit results in Figure 4, the estimates from Model 7 from Table 2 were used, as it had the lowest BIC of
} 
Table 2: Tobit Models of Correlation of Perceived Ideological Space with True Ideological Space

\begin{tabular}{|c|c|c|c|c|c|c|}
\hline & Model 7 & Model 8 & Model 9 & Model 10 & Model 11 & Model 12 \\
\hline Neuroticism & $\begin{array}{l}-0.202^{* * * *} \\
(0.075)\end{array}$ & $\begin{array}{c}-0.189^{* *} \\
(0.077)\end{array}$ & $\begin{array}{c}-0.156^{* *} \\
(0.075)\end{array}$ & $\begin{array}{l}-0.144^{*} \\
(0.075)\end{array}$ & $\begin{array}{l}-0.140^{*} \\
(0.075)\end{array}$ & $\begin{array}{l}-0.149^{* *} \\
(0.075)\end{array}$ \\
\hline Conscientiousness & $\begin{array}{l}0.174^{* *} \\
(0.083)\end{array}$ & $\begin{array}{l}0.155^{*} \\
(0.085)\end{array}$ & $\begin{array}{l}0.116 \\
(0.083)\end{array}$ & $\begin{array}{l}0.127 \\
(0.084)\end{array}$ & $\begin{array}{l}0.127 \\
(0.084)\end{array}$ & $\begin{array}{l}0.145^{*} \\
(0.084)\end{array}$ \\
\hline Agreeableness & $\begin{array}{l}-0.019 \\
(0.085)\end{array}$ & $\begin{array}{l}-0.006 \\
(0.089)\end{array}$ & $\begin{array}{c}0.041 \\
(0.088)\end{array}$ & $\begin{array}{l}0.038 \\
(0.087)\end{array}$ & $\begin{array}{l}0.037 \\
(0.087)\end{array}$ & $\begin{array}{c}0.042 \\
(0.087)\end{array}$ \\
\hline Extraversion & $\begin{array}{l}-0.103 \\
(0.064)\end{array}$ & $\begin{array}{l}-0.103 \\
(0.064)\end{array}$ & $\begin{array}{l}-0.089 \\
(0.062)\end{array}$ & $\begin{array}{l}-0.098 \\
(0.062)\end{array}$ & $\begin{aligned}-0.105^{*} \\
(0.062)\end{aligned}$ & $\begin{array}{c}-0.111^{*} \\
(0.062)\end{array}$ \\
\hline Openness & $\begin{array}{l}0.154^{*} \\
(0.083)\end{array}$ & $\begin{array}{l}0.154^{*} \\
(0.083)\end{array}$ & $\begin{array}{c}0.079 \\
(0.082)\end{array}$ & $\begin{array}{l}0.059 \\
(0.082)\end{array}$ & $\begin{array}{c}0.062 \\
(0.082)\end{array}$ & $\begin{array}{c}0.045 \\
(0.083)\end{array}$ \\
\hline Female & & $\begin{array}{l}-0.030 \\
(0.031)\end{array}$ & $\begin{array}{l}-0.020 \\
(0.030)\end{array}$ & $\begin{array}{l}-0.006 \\
(0.031)\end{array}$ & $\begin{array}{l}-0.003 \\
(0.031)\end{array}$ & $\begin{array}{l}-0.003 \\
(0.031)\end{array}$ \\
\hline Age & & $\begin{array}{l}-0.005 \\
(0.005)\end{array}$ & $\begin{array}{l}-0.004 \\
(0.005)\end{array}$ & $\begin{array}{l}-0.005 \\
(0.005)\end{array}$ & $\begin{array}{l}-0.006 \\
(0.005)\end{array}$ & $\begin{array}{l}-0.008 \\
(0.005)\end{array}$ \\
\hline $\mathrm{Age}^{2} / 100$ & & $\begin{array}{l}0.006 \\
(0.005)\end{array}$ & $\begin{array}{l}0.006 \\
(0.005)\end{array}$ & $\begin{array}{l}0.006 \\
(0.005)\end{array}$ & $\begin{array}{l}0.006 \\
(0.005)\end{array}$ & $\begin{array}{l}0.010^{*} \\
(0.006)\end{array}$ \\
\hline Black & & $\begin{array}{r}-0.092^{*} \\
(0.051)\end{array}$ & $\begin{array}{l}-0.093^{*} \\
(0.049)\end{array}$ & $\begin{array}{l}-0.080 \\
(0.049)\end{array}$ & $\begin{array}{l}-0.071 \\
(0.050)\end{array}$ & $\begin{array}{l}-0.066 \\
(0.050)\end{array}$ \\
\hline Hispanic & & $\begin{array}{l}-0.058 \\
(0.062)\end{array}$ & $\begin{array}{l}-0.052 \\
(0.061)\end{array}$ & $\begin{array}{l}-0.037 \\
(0.061)\end{array}$ & $\begin{array}{l}-0.030 \\
(0.061)\end{array}$ & $\begin{array}{l}-0.024 \\
(0.061)\end{array}$ \\
\hline Other Race & & $\begin{array}{l}0.008 \\
(0.057)\end{array}$ & $\begin{array}{l}0.006 \\
(0.056)\end{array}$ & $\begin{array}{l}-0.001 \\
(0.056)\end{array}$ & $\begin{array}{l}0.004 \\
(0.056)\end{array}$ & $\begin{array}{c}0.001 \\
(0.056)\end{array}$ \\
\hline Education $(1=$ No HS; $6=$ Postgrad $)$ & & & $\begin{array}{l}0.057^{* * *} \\
(0.010)\end{array}$ & $\begin{array}{l}0.050^{* * *} \\
(0.010)\end{array}$ & $\begin{array}{l}0.046^{* * *} \\
(0.011)\end{array}$ & $\begin{array}{c}0.045^{* * *} \\
(0.011)\end{array}$ \\
\hline High News Interest & & & & $\begin{array}{l}0.092^{* * *} \\
(0.032)\end{array}$ & $\begin{array}{l}0.088^{* * *} \\
(0.032)\end{array}$ & $\begin{array}{l}0.089^{* * *} \\
(0.032)\end{array}$ \\
\hline Unknown News Interest & & & & $\begin{array}{c}0.062 \\
(0.140)\end{array}$ & $\begin{array}{c}0.049 \\
(0.140)\end{array}$ & $\begin{array}{l}0.037 \\
(0.140)\end{array}$ \\
\hline Income $(1=<10 \mathrm{k} ; 12=>150 \mathrm{k} ; 13=$ Refused $)$ & & & & & $\begin{array}{l}0.006 \\
(0.005)\end{array}$ & $\begin{array}{l}0.008 \\
(0.005)\end{array}$ \\
\hline Income Refused & & & & & $\begin{array}{l}0.016 \\
(0.057)\end{array}$ & $\begin{array}{l}0.008 \\
(0.058)\end{array}$ \\
\hline Employed Full-Time & & & & & & $\begin{array}{c}0.015 \\
(0.041)\end{array}$ \\
\hline Employed Part-Time & & & & & & $\begin{array}{l}0.008 \\
(0.054)\end{array}$ \\
\hline Unemployed & & & & & & $\begin{array}{l}0.136^{*} \\
(0.072)\end{array}$ \\
\hline Retired & & & & & & $\begin{array}{l}-0.041 \\
(0.053)\end{array}$ \\
\hline Constant & $\begin{array}{c}0.662^{* * *} \\
(0.105)\end{array}$ & $\begin{array}{c}0.778^{* * *} \\
(0.168)\end{array}$ & $\begin{array}{c}0.551^{* * *} \\
(0.168)\end{array}$ & $\begin{array}{c}0.576^{* * *} \\
(0.168)\end{array}$ & $\begin{array}{c}0.557^{* * * *} \\
(0.168)\end{array}$ & $\begin{array}{c}0.581^{* * *} \\
(0.169)\end{array}$ \\
\hline $\operatorname{Ln}($ scale $)$ & $\begin{array}{c}-0.946^{* * *} \\
(0.026) \\
\end{array}$ & $\begin{array}{c}-0.953^{* * *} \\
(0.026) \\
\end{array}$ & $\begin{array}{c}-0.976^{* * * *} \\
(0.026) \\
\end{array}$ & $\begin{array}{c}-0.982^{* * *} \\
(0.026) \\
\end{array}$ & $\begin{array}{c}-0.984^{* * *} \\
(0.026)\end{array}$ & $\begin{array}{c}-0.988^{* * * *} \\
(0.026) \\
\end{array}$ \\
\hline AIC & 707.541 & 710.092 & 678.200 & 673.979 & 675.268 & 677.963 \\
\hline $\begin{array}{l}\text { Log Likelihood } \\
\text { Num obs. }\end{array}$ & $\begin{array}{c}-346.770 \\
722\end{array}$ & $\begin{array}{c}-342.046 \\
722\end{array}$ & $\begin{array}{c}-325.100 \\
722\end{array}$ & $\begin{array}{c}-320.989 \\
722\end{array}$ & $\begin{array}{c}-319.634 \\
722\end{array}$ & $\begin{array}{c}-316.981 \\
722\end{array}$ \\
\hline Cens. Obs. & 6 & 6 & 6 & 6 & 6 & 6 \\
\hline
\end{tabular}

Note: Standard errors in parentheses. Two-tailed tests: ${ }^{* * *} p<0.01,{ }^{* *} p<0.05,{ }^{*} p<0.1$

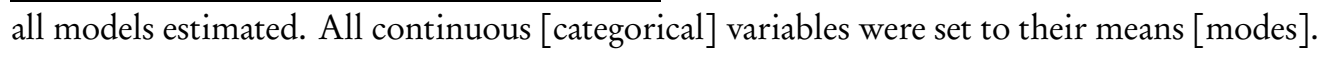


tion of the perceived space with the true space decreases from about 0.856 (when Neuroticism is set to two standard deviations below its mean) to about 0.677 (when set to two above its mean).

However, the results thus far do not allow us to analyze the underlying decisionmaking process, nor do they allow us to distinguish between different kinds of NA/DK responses. Thus, we shift our focus to the hierarchical model outlined earlier. ${ }^{19}$ For this model, the regressors included in the Opinion Intercept regression are all independent variables contained in Models 6 and 12 from Tables 1 and 2. These same variables are used in the Opinion Slope, Saliency Intercept, and Decisiveness regressions. To estimate the stimuli-dependent slopes in the Saliency regression, we create an indicator variable that equals 1 if the stimulus is of the same party as the respondent, and 0 otherwise (Copartisan). ${ }^{20}$ Finally, on the seven-point scale, we set 3 ("Somewhat Liberal") and 5 ("Somewhat Conservative") to be the bounds of the indifference region.

Table 3 presents the means of the estimated posterior distributions, and Figure 5 presents the estimated posterior distributions for the ideologies of the stimuli, as well as point estimates from the Aldrich-McKelvey estimation. ${ }^{21,22}$ To identify the scale for the hierarchical model, the ideologies of President Obama and Senator Ted Cruz are fixed at -1 and 1, respectively. All posterior distributions are tight, and correlate highly $\left(R^{2} \approx 0.9896\right)$ with those recovered from the Aldrich-McKelvey estimation, suggesting that the hierarchical model effectively taps into the same dimension as the Aldrich-McKelvey method, with the advantage of being able to provide information about the latent decisionmaking process, a feature we will exploit later.

Table 3 indicate Neuroticism has a negative relationship with the slope in the Opinion equa-

\footnotetext{
${ }^{19}$ For our analyses below, we ran the model for 70,000 draws each for four chains (with an additional tuning period of 10,000 draws per chain), burned the first 20,000 draws per chain, and applied a thinning interval of 10 to the remaining draws to reduce autocorrelation, thus leaving us with 5,000 draws per chain from the posterior distribution. As we show in the online Appendix, the standard Gelman-Rubin (1992) diagnostic suggests convergence was achieved for all parameters. Results are substantively identical if the original (unthinned) chains are used.

${ }^{20}$ The Democratic Party, Barack Obama, and Hillary Clinton were coded as Democratic. The Republican Party, the Tea Party, the Supreme Court, Ted Cruz, Jeb Bush, and Rand Paul were coded as Republican.

${ }^{21}$ For presentational purposes, the Aldrich-McKelvey estimates are linearly rescaled to ensure that the estimates of President Obama and Ted Cruz are -1 and 1, respectively. This rescaling has zero effect on the reported correlation.

${ }^{22}$ Model diagnostics are in the supplementary Appendix.
} 


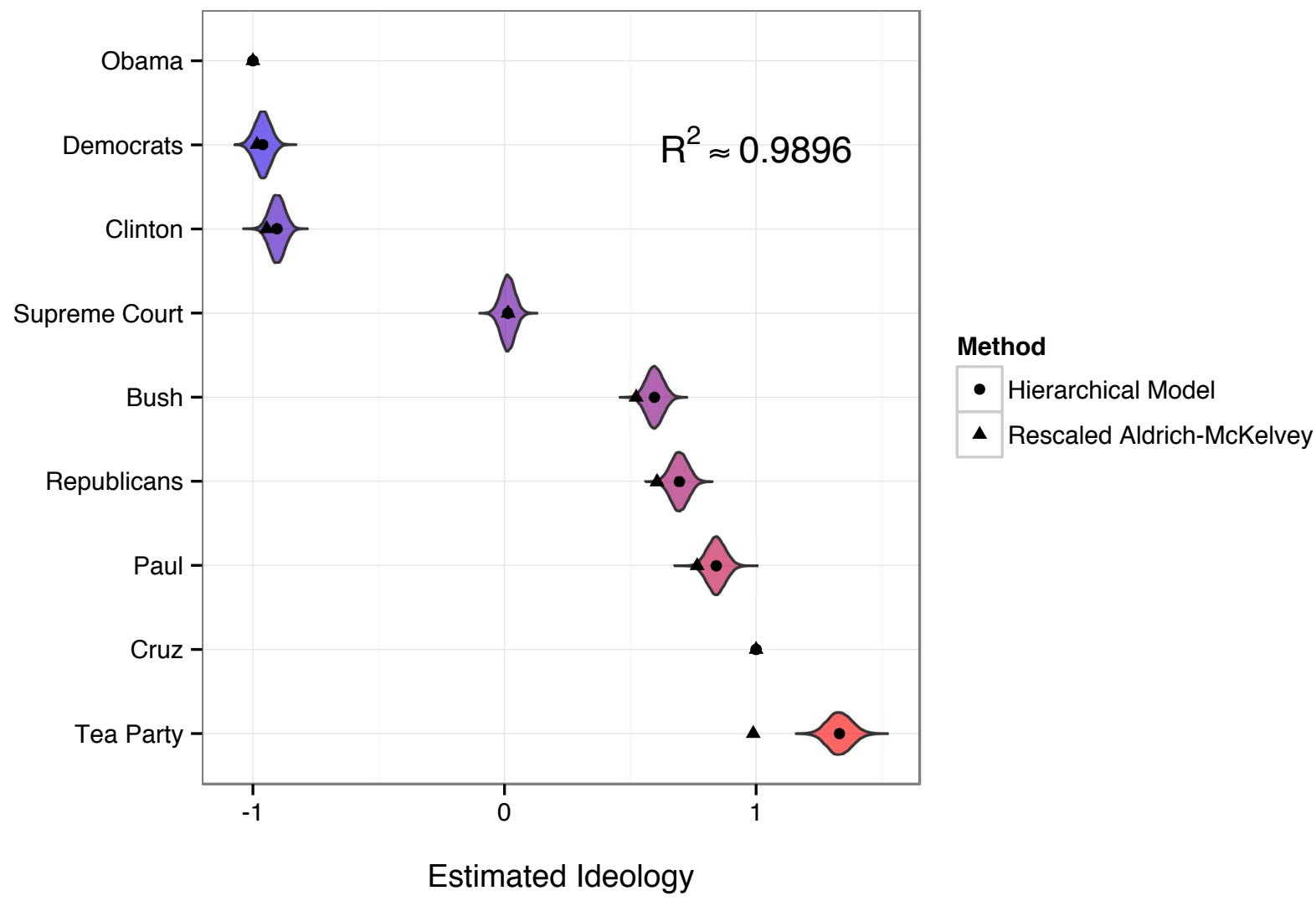

Figure 5: Comparison of Estimated Ideology of Stimuli using the Aldrich-McKelvey Method Versus the Hierarchical Model. Points for the hierarchical model indicate median estimates, and the violin plots indicate the posterior distributions; placements of Obama and Cruz are fixed at -1 and 1 respectively to identify the scale.

tion, which is illustrated in Figure 6; indeed, over 98\% of the posterior distribution lies to the left of zero. This suggests Neuroticism is associated with ideological placement being less highly correlated with the underlying ideological space, a result consistent with those from the AldrichMcKelvey models, and in further support of Hypothesis 4.

One draw of the hierarchical model is its ability to model the decisionmaking process and pinpoint why Neurotic individuals are more likely to provide NA/DKs. In the Saliency intercept equation in Table 3, the coefficient on Neuroticism is negative, and the $80 \%$ HPD interval does 

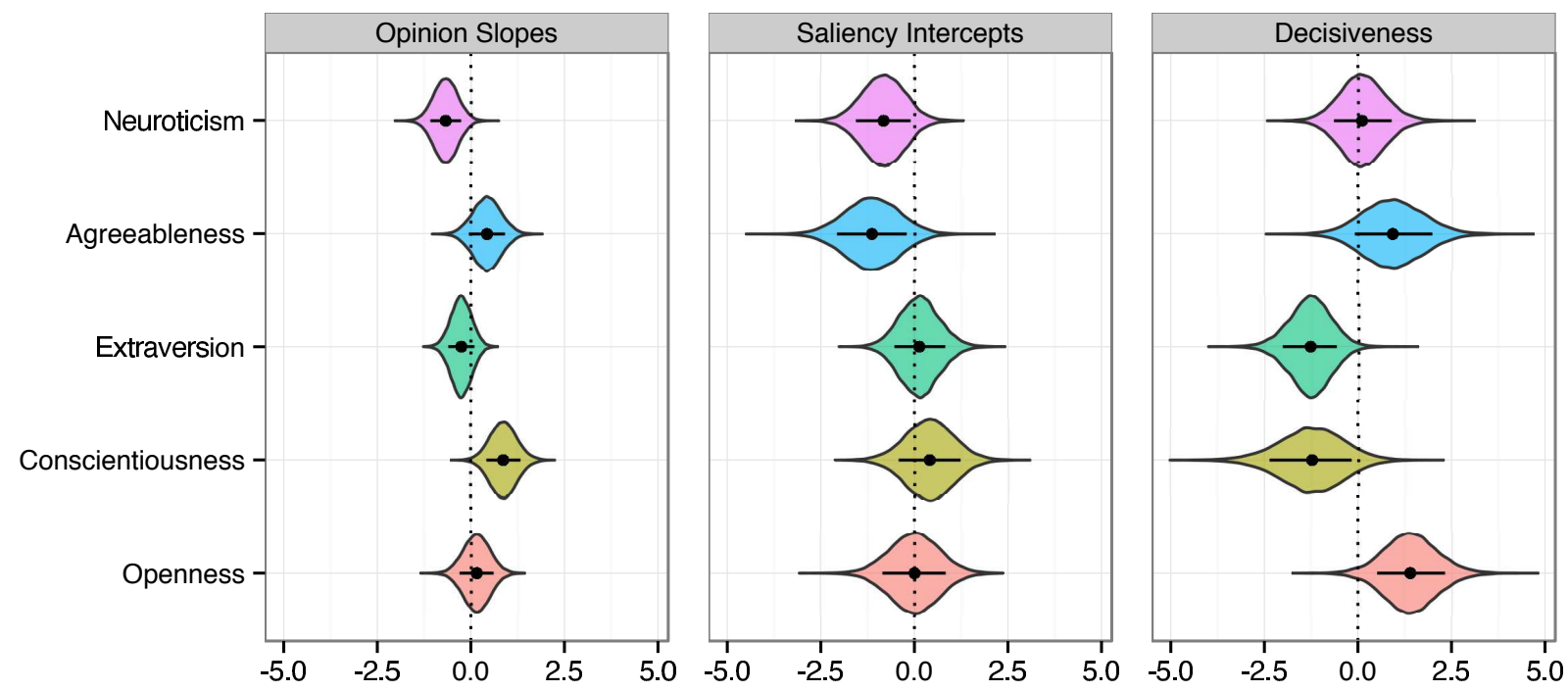

Coefficient Estimate

Figure 6: Posterior Distributions of Estimated Effects of Traits on Opinion Slopes, Saliency Intercepts, and Decisiveness. Points indicate medians. Bars indicate middle $80 \%$ of distributions.

not contain zero. ${ }^{23}$ These results suggest Neurotic individuals are less likely to find the stimuli salient, increasing the probability of NA/DKs, in support of Hypothesis 2. Additionally, political interest is associated with higher saliency intercepts, suggesting those who are more politically interested are more likely to find the stimuli salient and therefore less likely to provide NA/DKs.

Turning to the Decisiveness equation, we find less support for our relevant hypothesis (Hypothesis 1), further illustrated in Figure 6. Indeed, the estimate for the coefficient on Neuroticism is close to zero, and the 5\% HPD interval for this coefficient is the largest one that does not contain zero, providing strong evidence against Hypothesis 1's prediction of Neuroticism being negatively associated with decisiveness. Moreover, $43 \%$ of the posterior distribution lies to the left of zero, and $57 \%$ lies to the right, indicating near-symmetric uncertainty about zero. Indeed, these results suggest the larger proportion of NA/DK responses (in support of Hypothesis 3) is due to inhibition-as opposed to indecision-on the part of Neurotics.

\footnotetext{
${ }^{23}$ Over $93 \%$ of the posterior distribution for this estimate lies to the left of zero.
} 
Table 3: Hierarchical Model Results

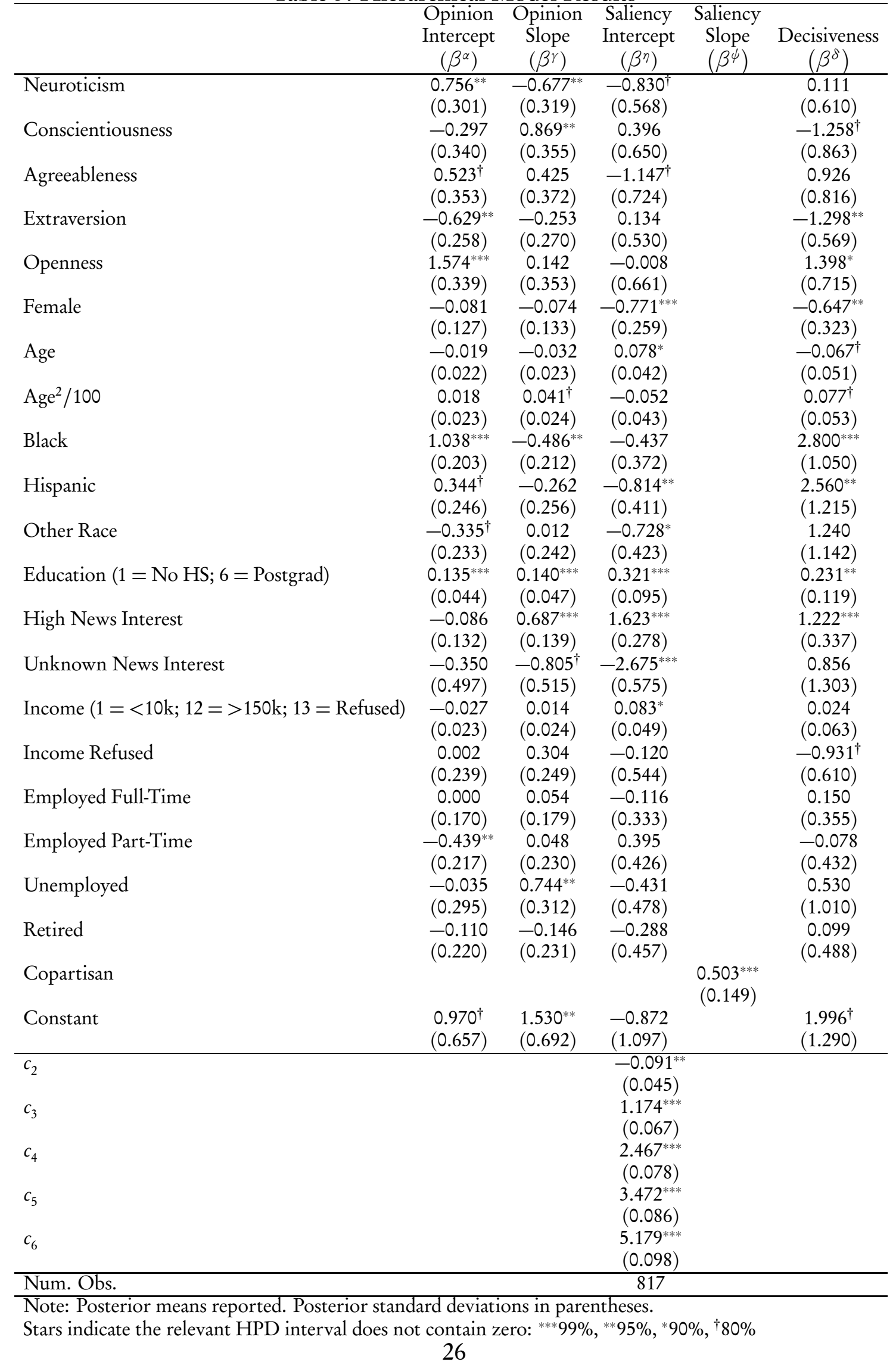


Overall, our analysis suggests more Neurotic individuals are more likely to provide NA/DK responses to ideological placement questions on political surveys, are less likely to accurately perceive the underlying ideological space, and that this is at least in part due to these questions being less salient to these individuals. We have also uncovered evidence that this response pattern is not due to more Neurotic individuals being less decisive, in contrast to our expectations. Nonetheless, these results support our conception of Neuroticism as being a proxy for sensitivity to punishment. Moreover, they suggest the mechanism is one of inhibition as opposed to indecisiveness. Finally, the hierarchical model is able to go further than traditional methods of addressing NA/DK responses and look at the factors influencing saliency and decisiveness across individuals; the significant coefficients in all equations are prima facie evidence that more conventional methods might result in incorrect inferences, suggesting that this model will help scholars to better understand the processes that lead to NA/DK responses in survey data.

\section{Discussion and Conclusion}

This paper introduces to political science a Bayesian hierarchical model for ordinal data that allows for NA/DK responses to be driven by latent psychological processes. While our interests here are in the effects of Neuroticism, this framework can be applied to any similar setup, thus allowing scholars to better model decisionmaking processes and generate more reliable estimates of effects. Importantly, the ideological estimates produced by this model are nearly identical to those produced to the Aldrich-McKelvey model, suggesting that that both tap into the same ideological dimension. However, the ability of the hierarchical model to provide us information about the underlying decisionmaking process gives it an advantage beyond the traditional Aldrich-McKelvey method (and ordered probit). That said, it should be noted that the original Bradlow \& Zaslavsky (1999) model was designed for consumer satisfaction surveys, and is therefore an imperfect fit to the data used here; arguably, the middle categories in satisfaction surveys 
more clearly represent "indifference" than those on ideological scales. However, that we generate nearly identical estimates of perceived ideology across both methods suggests this is not a major problem and that the model works appropriately with empirical data. Nonetheless, we plan in the future to leverage this model and apply it to the study of political approval. Furthermore, the empirical and theoretical models may be adapted to situations in which penalties may be derived from social indesirability rather than inaccuracy of opinion.

Substantively, we have found evidence Neuroticism is associated with higher rates of NA/DK responses on surveys and an inability to correctly place political figures on an ideological scale. Additionally, we have argued that these higher rates of NA/DKs are in part due to reduced salience for more Neurotic individuals as opposed to higher rates of indecisiveness. More broadly, these results are consistent with a theory of opinion formation (and reporting) and information acquisition based on a model of Neuroticism as representing a core cognitive constraint of sensitivity to punishment. The effect of Neuroticism on salience compared to decisiveness is consistent with our theory that more Neurotic individuals, looking down the game tree in everyday contexts, identify contexts in which they will choose to be indecisive, and select to avoid collecting costly information in anticipation of that decision.

That Neuroticism is associated with lower salience but not with decisiveness provides support for the model-derived hypothesis that Neuroticism is associated with a decision to avoid paying for costly information, but does not provide support for the hypothesis that Neuroticism is associated with the decision not to form a belief. This would appear to be a puzzle for our theory. However, our model assumes an incorrect response carries a penalty, which may not hold for the data used here, which was collected through an Internet survey. In the absence of a personal interviewer, there may be no penalty for incorrect responses, which would result in no theoretical relationship between Neuroticism and decisiveness. In the course of everyday conversations where individuals dispute political facts and provide social penalties for incorrect assertions, the mechanism we outline would hold, promoting indecisiveness and a lack of information-gathering 
among Neurotics. Future work incorporating clear punishments for incorrect assertions through face-to-face survey administration, verification, and/or material punishments for incorrect responses is necessary to resolve this puzzle.

Additionally, our results speak to the larger body of work on uncertainty. While much of the previous psychological work has focused on the role of personality and its role in opinion uncertainty (e.g., Flehmig et al. 2007, Mondak et al. 2010, Robinson \& Tamir 2005), other political science work has focused more on opinion uncertainty as a function of education, political interest, and other demographic variables (e.g., Alvarez \& Franklin 1994, Bartels 1986, Delli Carpini \& Keeter 1996, Jackson 1993). ${ }^{24}$ One of the benefits of our model is that it estimates NA/DK responses as functions of three latent factors (salience, opinion, and decisiveness), and these factors themselves are estimated as functions of personality traits and demographic variables (while allowing for the inclusion of other variables), thus unifying much of the previous literature on nonresponse.

Going forth, we plan on leveraging the framework of Ramey, Klingler \& Hollibaugh (2015b) to link personality traits to a wide variety of political behavior via core cognitive constraints, with the intent of framing underlying psychological processes in terms that may be incorporated into formal models. Indeed, this paper has shown one way they may be formalized and tested, and provides a blueprint for future scholars to incorporate personality traits into their own research.

\footnotetext{
${ }^{24}$ Other research investigates the role of value conflict (e.g., Alvarez \& Brehm 2002).
} 


\section{References}

Aldrich, John H. \& Richard D. McKelvey. 1977. "A Method of Scaling with Applications to the 1968 and 1972 Presidential Elections." American Political Science Review 71(1):111-130.

Allison, P.D. 2009. Missing Data. In The SAGE Handbook of Quantitative Methods in Psychology, ed. Roger E. Millsap \& Alberto Maydeu-Olivares. Thousand Oaks, CA: SAGE Publications.

Almlund, Mathilde, Angela Lee Duckworth, James Heckman \& Tim Kautz. 2011. Personality Psychology and Economics. In Handbook of the Economics of Education, ed. Eric A. Hanushek, Stephen Machin \& Ludger Woessmann. Elsevier pp. 1-181.

Alvarez, R. Michael. 1999. Information and Elections. Ann Arbor: University of Michigan Press.

Alvarez, R. Michael \& Charles H. Franklin. 1994. "Uncertainty and Political Perceptions.” Journal of Politics 56(3):671-688.

Alvarez, R. Michael \& John Brehm. 2002. Hard Choices, Easy Answers: Values, Information, and American Public Opinion. Princeton, NJ: Princeton University Press.

Bartels, Larry M. 1986. “Issue Voting Under Uncertainty: An Empirical Test.” American Journal of Political Science 30(4):709-728.

Bartels, Larry M. 1999. "Panel Effects in the American National Election Studies." Political Analysis 8(1):1-20.

Berinsky, Adam J. 1999. "The Two Faces of Public Opinion.” American Journal of Political Science 43(4):1209-1230.

Block, Jack. 1995. “A Contrarian View of the Five-Factor Approach to Personality Description.” Psychological Bulletin 117(2):187. 
Bradlow, Eric T. \& Alan M. Zaslavsky. 1999. “A Hierarchical Latent Variable Model for Ordinal Data from a Customer Satisfaction Survey with "No Answer" Responses." Journal of the American Statistical Association 94(445):43-52.

Brehm, John. 1993. The Phantom Respondents: Opinion Surveys and Political Representation. Ann Arbor: University of Michigan Press.

Delli Carpini, Michael X. \& Scott Keeter. 1996. What Americans Know about Politics and Why It Matters. New Haven: Yale University Press.

Depue, Richard A. \& Paul F. Collins. 1999. "Neurobiology of the Structure of Personality: Dopamine, Facilitation of Incentive Motivation, and Extraversion." Behavioral and Brain Sciences 22(3):491-517.

Derryberry, Douglas \& Marjorie A. Reed. 1994. “Temperament and Attention: Orienting Toward and Away From Positive and Negative Signals." Journal of Personality and Social Psychology 66(6):1128-1139.

DeYoung, Colin G. \& Jeremy R. Gray. 2009. Personality Neuroscience: Explaining Individual Differences in Affect, Behavior, and Cognition. In The Cambridge Handbook of Personality Psychology, ed. Philip J. Corr \& Gerald Matthews. New York: Cambridge University Press pp. 323-346.

Dietrich, Bryce J., Scott Lasley, Jeffery J. Mondak, Megan L. Remmel \& Joel Turner. 2012. "Personality and Legislative Politics: The Big Five Trait Dimensions Among U.S. State Legislators." Political Psychology 33(2):195-210.

Ehrhart, Mark G., Karen Holcombe Ehrhart, Scott C. Roesch, Beth G. Chung-Herrera, Kristy Nadler \& Kelsey Bradshaw. 2009. “Testing the latent factor structure and construct validity of the Ten-Item Personality Inventory." Personality and Individual Differences 47(8):900905. 
Eysenck, Hans J. 1992. "Four ways five factors are not basic." Personality and Individual Differences 13(6):667-673.

Flehmig, Hagen C., Michael Steinborn, Robert Langner \& Karl Westhoff. 2007. "Neuroticism and the mental noise hypothesis: Relationships to lapses of attention and slips of action in everyday life." Psychology Science 49(4):343-360.

Fraley, R. Chris \& Brent W. Roberts. 2005. "Patterns of Continuity: A Dynamic Model for Conceptualizing the Stability of Individual Differences in Psychological Constructs Across the Life Course." Psychological Review 112(1):60-74.

Gelman, Andrew \& Donald B. Rubin. 1992. "Inference from Iterative Simulation Using Multiple Sequences." Statistical Science 7(4):457-511.

Gelman, Andrew, Gary King \& Chuanhai Liu. 1998. "Not Asked and Not Answered: Multiple Imputation for Multiple Surveys." Journal of the American Statistical Association 93(443):846-857.

Gerber, Alan S., Gregory A. Huber, David Doherty \& Conor M. Dowling. 2011a. “The Big Five Personality Traits in the Political Arena." Annual Review of Political Science 14(1):265-287.

Gerber, Alan S., Gregory A. Huber, David Doherty \& Conor M. Dowling. 2011b. "Personality Traits and the Consumption of Political Information." American Politics Research 39(1):3284.

Gerber, Alan S., Gregory A. Huber, David Doherty, Conor M. Dowling \& Shang E. Ha. 2010. "Personality and Political Attitudes: Relationships across Issue Domains and Political Contexts." American Political Science Review 104(1):111-133.

Glasgow, Garrett \& R. Michael Alvarez. 2000. “Uncertainty and Candidate Personality Traits.” American Politics Research 28(1):26-49. 
Goldberg, Lewis R. 1981. Language and Individual Differences: The Search for Universals in Personality Lexicons. In Review of Personality and Social Psychology, ed. Ladd Wheeler. Vol. 2 Beverly Hills, CA: Sage pp. 141-165.

Gosling, Samuel D., Peter J. Rentfrow \& William B. Swann, Jr. 2003. “A very brief measure of the Big-Five personality domains." Journal of Research in Personality 37(6):504-528.

Gray, Jeffrey A. \& Neil McNaughton. 2003. The Neuropsychology of Anxiety: An Enquiry into the Functions of the Septo-Hippocampal System. New York: Oxford University Press.

Hall, Matthew E. K. 2015. "Judging with Personality: A Psychoeconomic Model of Supreme Court Behavior.” Manuscript.

Hare, Christopher, David A. Armstrong, Ryan Bakker, Royce Carroll \& Keith T. Poole. 2014. “Using Bayesian Aldrich-McKelvey Scaling to Study Citizens' Ideological Preferences and Perceptions." American Journal of Political Science .

Heckman, James J. 1976. “The Common Structure of Statistical Models of Truncation, Sample Selection and Limited Dependent Variables and a Simple Estimator for Such Models." Annals of Economic and Social Measurement 5(4):475-492.

Hollibaugh, Jr., Gary E., Lawrence S. Rothenberg \& Kristin K. Rulison. 2013. “Does It Really Hurt to Be Out of Step?" Political Research Quarterly 66(4):856-867.

Holroyd, Clay B. \& Michael G. H. Coles. 2002. “The Neural Basis of Human Error Processing: Reinforcement Learning, Dopamine, and the Error-Related Negativity.” Psychological Review 109(4):679.

Jackson, John E. 1993. “Attitudes, No Opinions, and Guesses.” Political Analysis 5(1):39-60.

Jessee, Stephen A. 2015. ““Don’t Know” Responses, Personality, and the Measurement of Political Knowledge." Political Science Research and Methods Forthcoming. 
John, Oliver P. 1990. The "Big Five" Factor Taxonomy: Dimensions of Personality in the Natural Language and in Questionnaires. In Handbook of Personality: Theory and Research, ed. Lawrence A. Pervin \& Oliver P. John. New York: Guilford Press pp. 66-100.

John, Oliver P., Laura P. Naumann \& Christopher J. Soto. 2008. Paradigm Shift to the Integrative Big Five Trait Taxonomy. In Handbook of Personality: Theory and Research, ed. Oliver P. John, Richard W. Robins \& Lawrence A. Pervin. Vol. Third New York: Guilford Press pp. 114-158.

John, Oliver P., Richard W. Robins \& Lawrence A. Pervin. 2008. Handbook of Personality: Theory and Research. Third ed. New York: Guilford Press.

Kahneman, Daniel \& Amos Tversky. 1979. "Prospect Theory: An Analysis of Decision Under Risk." Econometrica 47(2):263-291.

King, Gary, James Honaker, Anne Joseph \& Kenneth Scheve. 2001. “Analyzing Incomplete Political Science Data: An Alternative Algorithm for Multiple Imputation.” American Political Science Review 95(1):49-69.

McCrae, Robert R. 1994. “Openness to experience: Expanding the boundaries of Factor V." European Journal of Personality 8(4):251-272.

McCrae, Robert R. \& Paul T. Costa, Jr. 1996. Toward a New Generation of Personality Theories: Theoretical Contexts for the Five-Factor Model. In The Five-Factor Model of Personality: Theoretical Perspectives, ed. Jerry S. Wiggins. New York: Guilford Press pp. 51-87.

Mondak, Jeffery J. \& Karen D. Halperin. 2008. “A Framework for the Study of Personality and Political Behaviour." British Journal of Political Science 38(2):335-362.

Mondak, Jeffery J., Matthew V. Hibbing, Damarys Canache, Mitchell A. Seligson \& Mary R. Anderson. 2010. "Personality and Civic Engagement: An Integrative Framework for the 
Study of Trait Effects on Political Behavior." American Political Science Review 104(1):85110.

Plummer, Martyn. 2003. JAGS: A Program for Analysis of Bayesian Graphical Models Using Gibbs Sampling. In Proceedings of the 3rd International Workshop on Distributed Statistical Computing, ed. Kurt Hornik, Friedrich Leisch \& Achim Zeileis. Vienna, Austria: Technische Universität Wien.

Poole, Keith T. 1998. "Recovering a Basic Space From a Set of Issue Scales.” American Journal of Political Science 42(3):954-993.

Ramey, Adam J., Jonathan D. Klingler \& Gary E. Hollibaugh, Jr. 2015a. "Talking Heads: Measuring Elite Personality Using Speech.” Manuscript.

Ramey, Adam J., Jonathan D. Klingler \& Gary E. Hollibaugh, Jr. 2015b. "Will I Stay Or Will I Go? Conscientiousness and Lame Duck Absenteeism in the United States Congress.” Manuscript.

Roberts, Brent W., Nathan R. Kuncel, Rebecca Shiner, Avshalom Caspi \& Lewis R. Goldberg. 2007. "The Power of Personality: The Comparative Validity of Personality Traits, Socioeconomic Status, and Cognitive Ability for Predicting Important Life Outcomes.” Perspectives on Psychological Science 2(4):313-345.

Roberts, Brent W. \& Wendy F. DelVecchio. 2000. "The Rank-Order Consistency of Personality Traits From Childhood to Old Age: A Quantitative Review of Longitudinal Studies.” Psychological Bulletin 126(1):3-25.

Robinson, Michael D. \& Maya Tamir. 2005. "Neuroticism as Mental Noise: A Relation Between Neuroticism and Reaction Time Standard Deviations." Journal of Personality and Social Psychology 89(1):107-114. 
Rubin, Donald B. 1976. "Inference and Missing Data.” Biometrika 63(3):581-592.

Rubin, Donald B. 1977. "Formalizing Subjective Notions About the Effect of Nonrespondents in Sample Surveys." Journal of the American Statistical Association 72(359):538-543.

Rubin, Donald B. 1987. Multiple Imputation for Nonresponse in Surveys. New York: Wiley.

Soldz, Stephen \& George E. Vaillant. 1999. "The Big Five Personality Traits and the Life Course: A 45-Year Longitudinal Study." Journal of Research in Personality 33(2):208-232.

Tversky, Amos \& Daniel Kahneman. 1992. "Advances in Prospect Theory: Cumulative Representation of Uncertainty." Journal of Risk and Uncertainty 5(4):297-323.

Weisberg, Herbert F. 2009. The Total Survey Error Approach: A Guide to the New Science of Survey Research. Chicago: University of Chicago Press.

Zaller, John \& Stanley Feldman. 1992. "A Simple Theory of the Survey Response: Answering Questions Versus Revealing Preferences.” American Journal of Political Science 36(3):579616. 


\section{Online Appendix A: Model Diagnostics}

Table A-1: Potential Scale Reduction Factors

\begin{tabular}{|c|c|c|c|c|c|}
\hline & $\begin{array}{c}\text { Opinion } \\
\text { Intercept } \\
\left(\beta^{\alpha}\right)\end{array}$ & $\begin{array}{c}\text { Opinion } \\
\text { Slope } \\
\left(\beta^{r}\right)\end{array}$ & $\begin{array}{c}\text { Saliency } \\
\text { Intercept } \\
\left(\beta^{\eta}\right)\end{array}$ & $\begin{array}{c}\text { Saliency } \\
\text { Slope } \\
\left(\beta^{\psi}\right)\end{array}$ & $\begin{array}{c}\text { Decisiveness } \\
\left(\beta^{\delta}\right)\end{array}$ \\
\hline Neuroticism & 1.00 & 1.01 & 1.01 & & 1.01 \\
\hline Conscientiousness & 1.00 & 1.00 & 1.02 & & 1.03 \\
\hline Agreeableness & 1.00 & 1.00 & 1.01 & & 1.02 \\
\hline Extraversion & 1.00 & 1.00 & 1.01 & & 1.01 \\
\hline Openness & 1.00 & 1.00 & 1.02 & & 1.03 \\
\hline Female & 1.00 & 1.00 & 1.00 & & 1.01 \\
\hline Age & 1.00 & 1.00 & 1.00 & & 1.01 \\
\hline $\mathrm{Age}^{2} / 100$ & 1.00 & 1.00 & 1.00 & & 1.00 \\
\hline Black & 1.00 & 1.00 & 1.05 & & 1.02 \\
\hline Hispanic & 1.00 & 1.00 & 1.03 & & 1.02 \\
\hline Other Race & 1.00 & 1.00 & 1.01 & & 1.05 \\
\hline Education $(1=$ No HS; $6=$ Postgrad $)$ & 1.00 & 1.00 & 1.01 & & 1.03 \\
\hline High News Interest & 1.00 & 1.00 & 1.04 & & 1.03 \\
\hline Unknown News Interest & 1.00 & 1.02 & 1.00 & & 1.02 \\
\hline Income $(1=<10 \mathrm{k} ; 12=>150 \mathrm{k} ; 13=$ Refused $)$ & 1.00 & 1.00 & 1.06 & & 1.03 \\
\hline Income Refused & 1.00 & 1.00 & 1.01 & & 1.02 \\
\hline Employed Full-Time & 1.00 & 1.00 & 1.02 & & 1.04 \\
\hline Employed Part-Time & 1.00 & 1.00 & 1.01 & & 1.01 \\
\hline Unemployed & 1.00 & 1.00 & 1.01 & & 1.06 \\
\hline Retired & 1.00 & 1.00 & 1.00 & & 1.01 \\
\hline Copartisan & & & & 1.05 & \\
\hline Constant & 1.00 & 1.00 & 1.00 & & 1.00 \\
\hline Obama & & & NA & & \\
\hline Cruz & & & NA & & \\
\hline Clinton & & & 1.00 & & \\
\hline Paul & & & 1.03 & & \\
\hline Bush & & & 1.04 & & \\
\hline Democrats & & & 1.01 & & \\
\hline Republicans & & & 1.05 & & \\
\hline Tea Party & & & 1.03 & & \\
\hline Supreme Court & & & 1.02 & & \\
\hline$c_{2}$ & & & 1.07 & & \\
\hline$c_{3}$ & & & 1.09 & & \\
\hline$c_{4}$ & & & 1.09 & & \\
\hline$c_{5}$ & & & 1.08 & & \\
\hline$c_{6}$ & & & 1.10 & & \\
\hline
\end{tabular}

Note: Upper bounds of the $95 \%$ confidence interval reported. The Gelman-Rubin (1992) statistic (referred to as the potential scale reduction factor [PSRF] or $\hat{R}$ ) measures convergence within and across chains by estimating the degree to which the scale of the current distribution for the parameter of interest might be reduced if the current simulations were continued to infinity. This factor declines to 1 as the number of draws approaches infinity. Values less than or equal to 1.10 suggest convergence. 

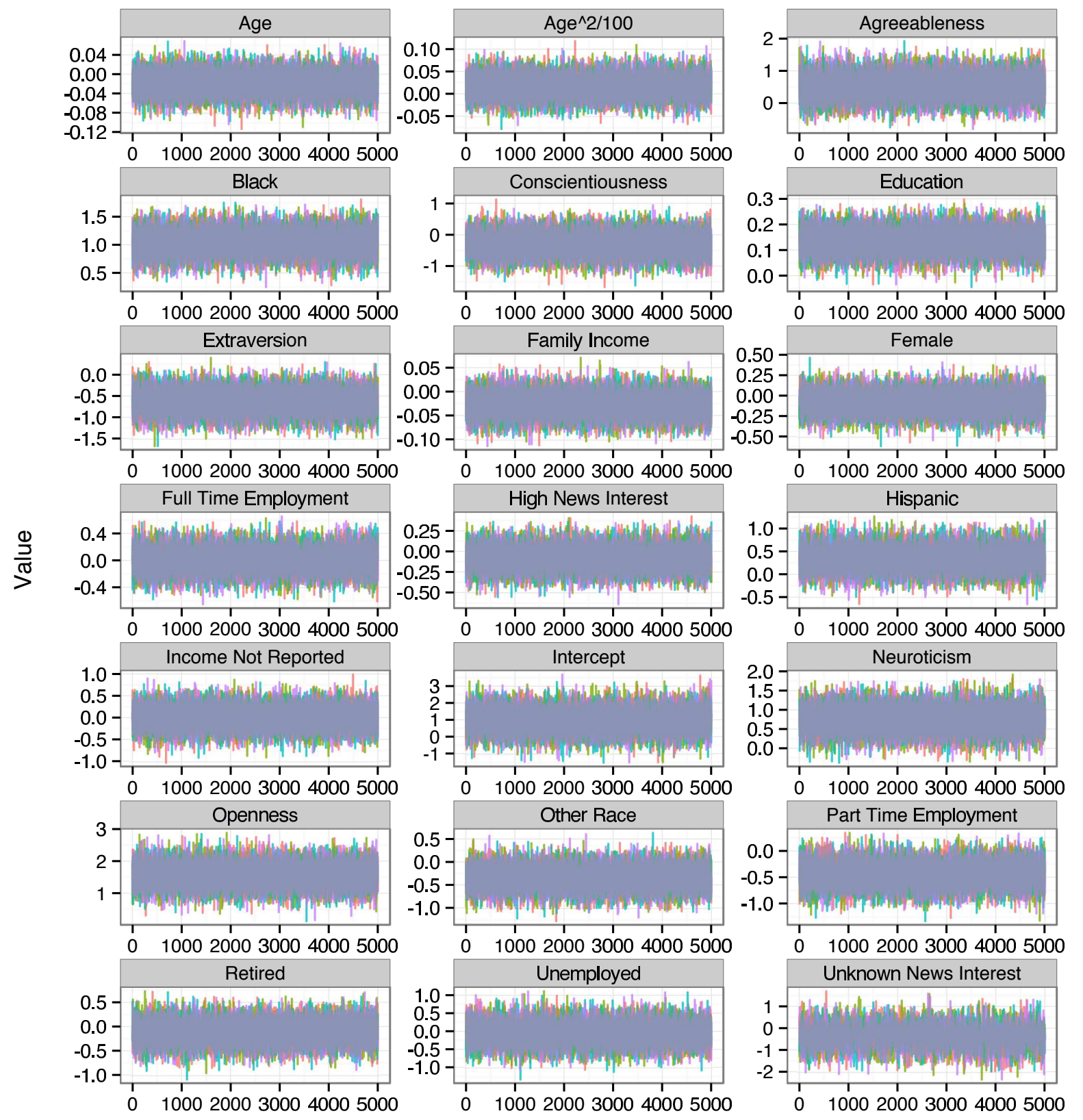

\section{Chain} -1
-2
-3
-4
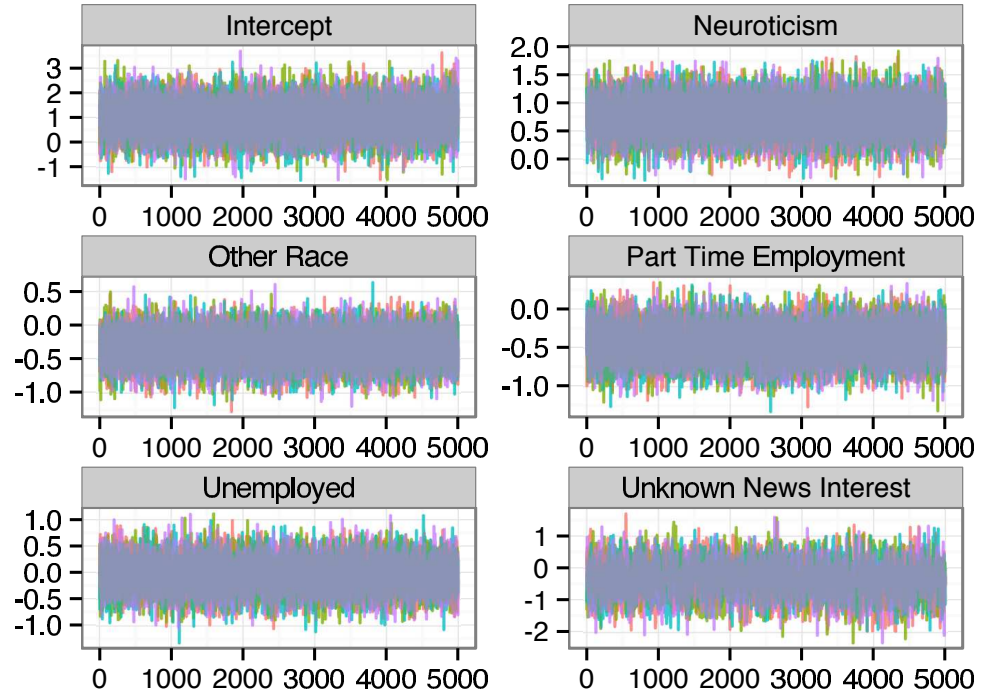

Iteration

Figure A-1: Traceplots of Opinion Intercept Coefficient Draws. 

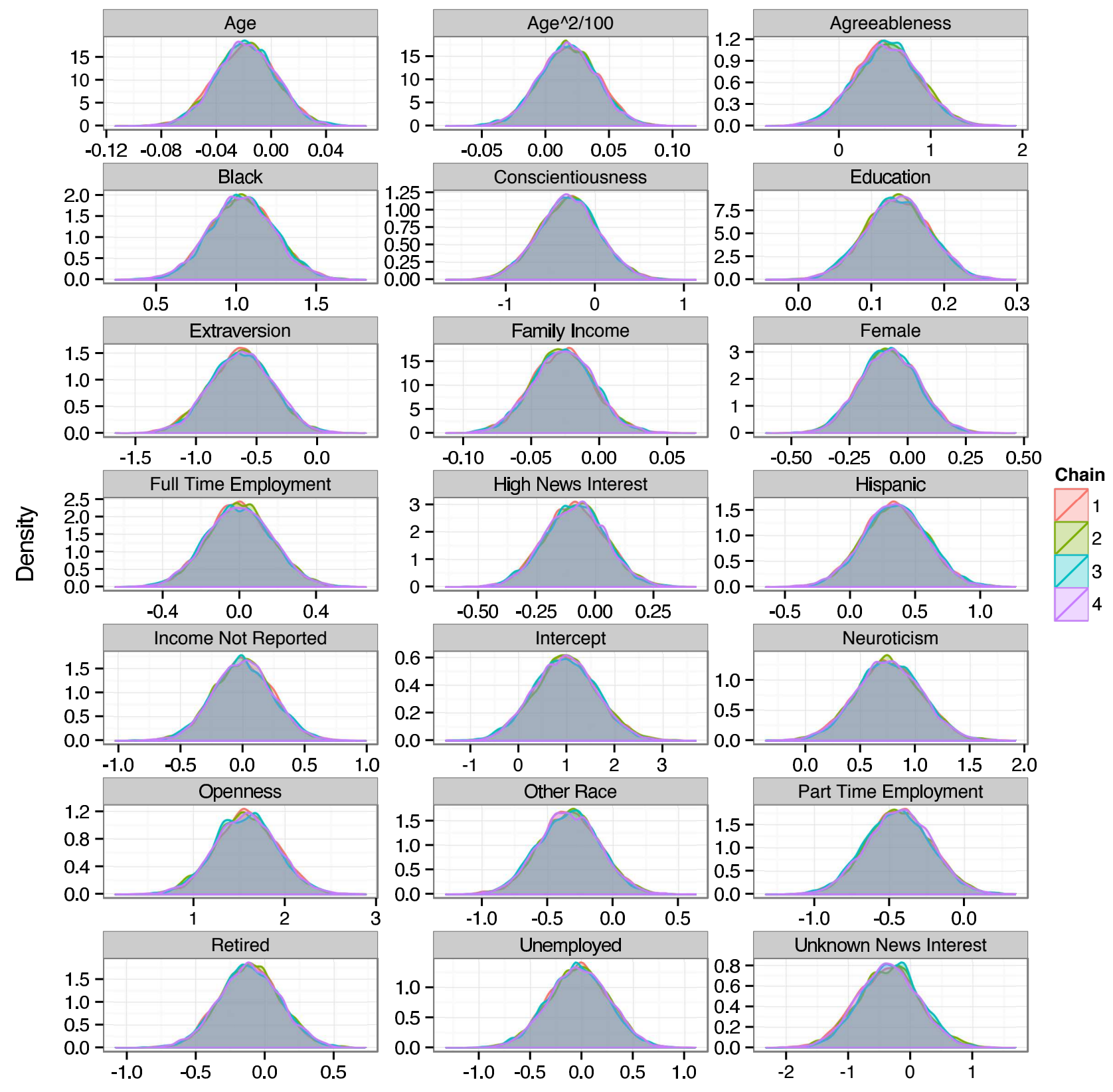

Value

Figure A-2: Density Plot of Opinion Intercept Coefficient Draws. 

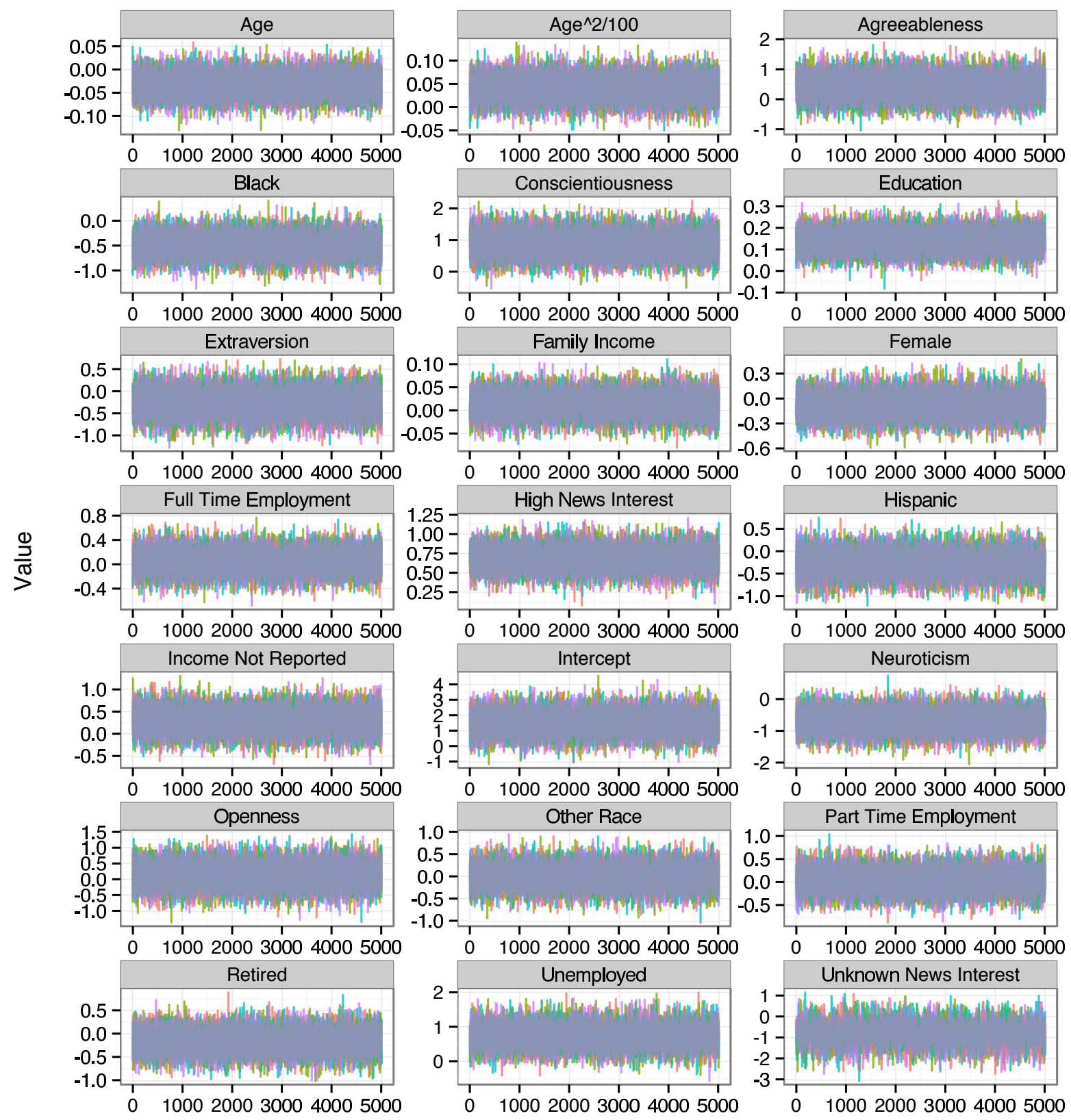

Iteration

Figure A-3: Traceplots of Opinion Slope Coefficient Draws. 

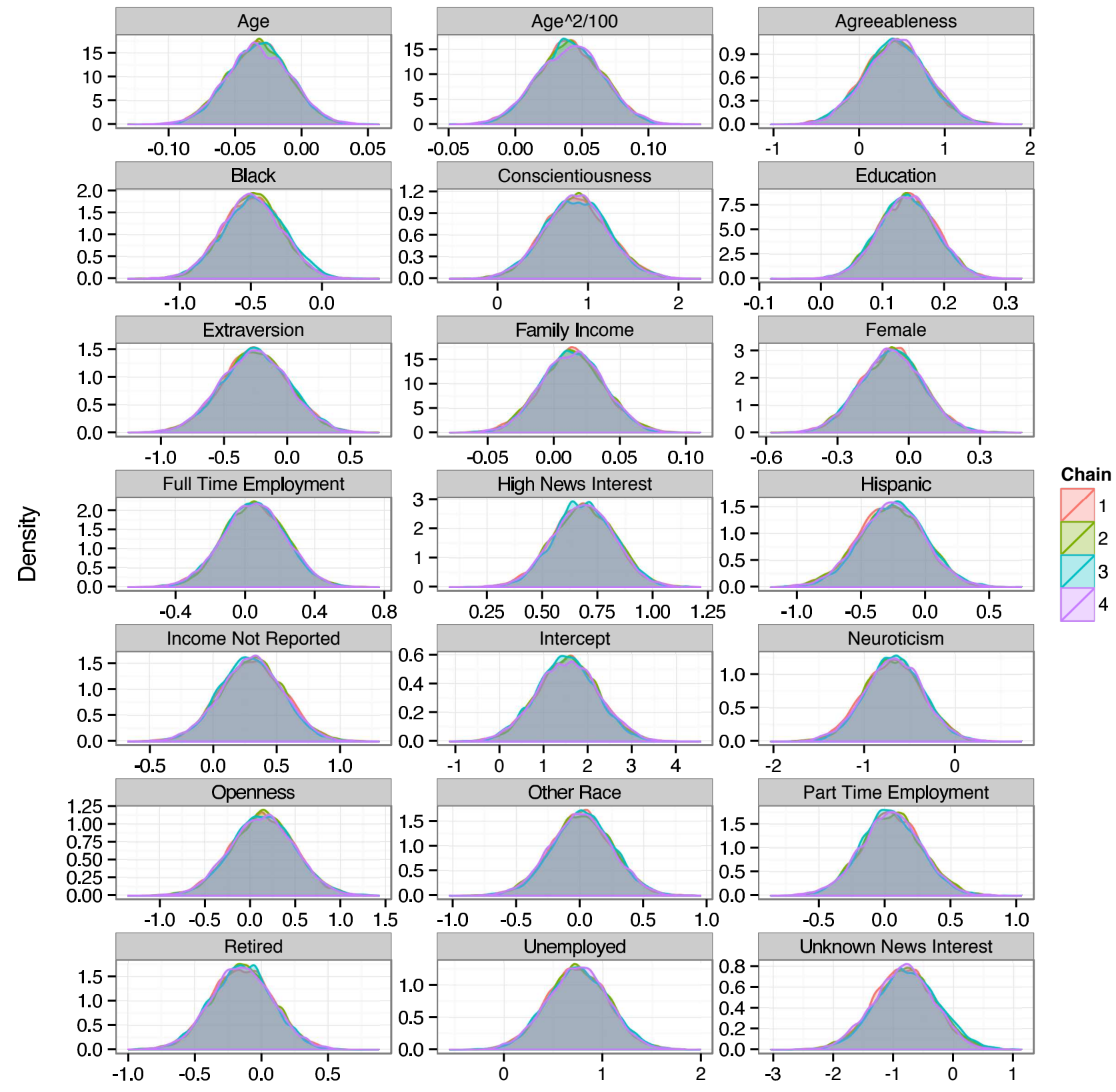

Value

Figure A4: Density Plot of Opinion Slope Coefficient Draws. 

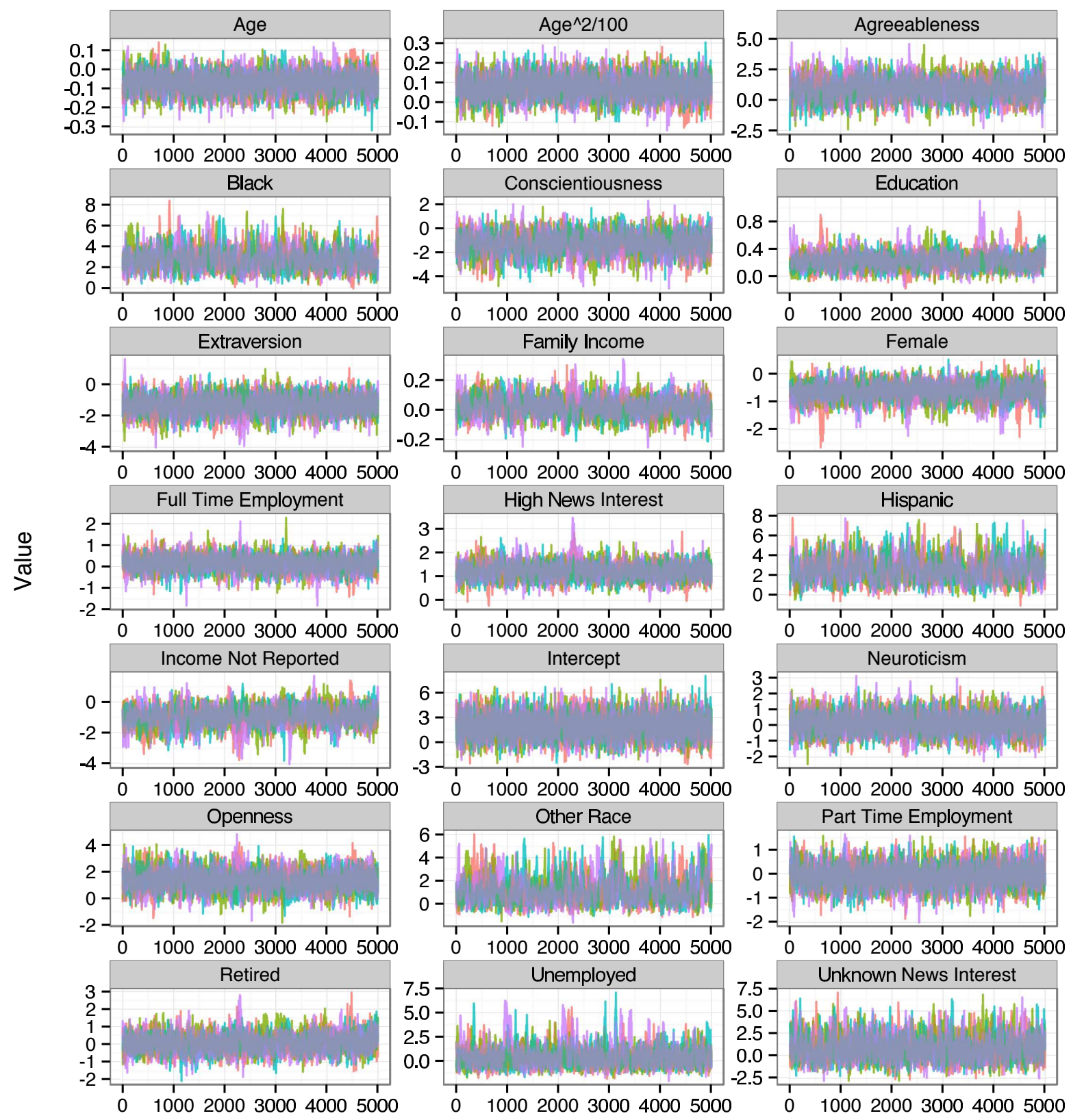

High News Interest
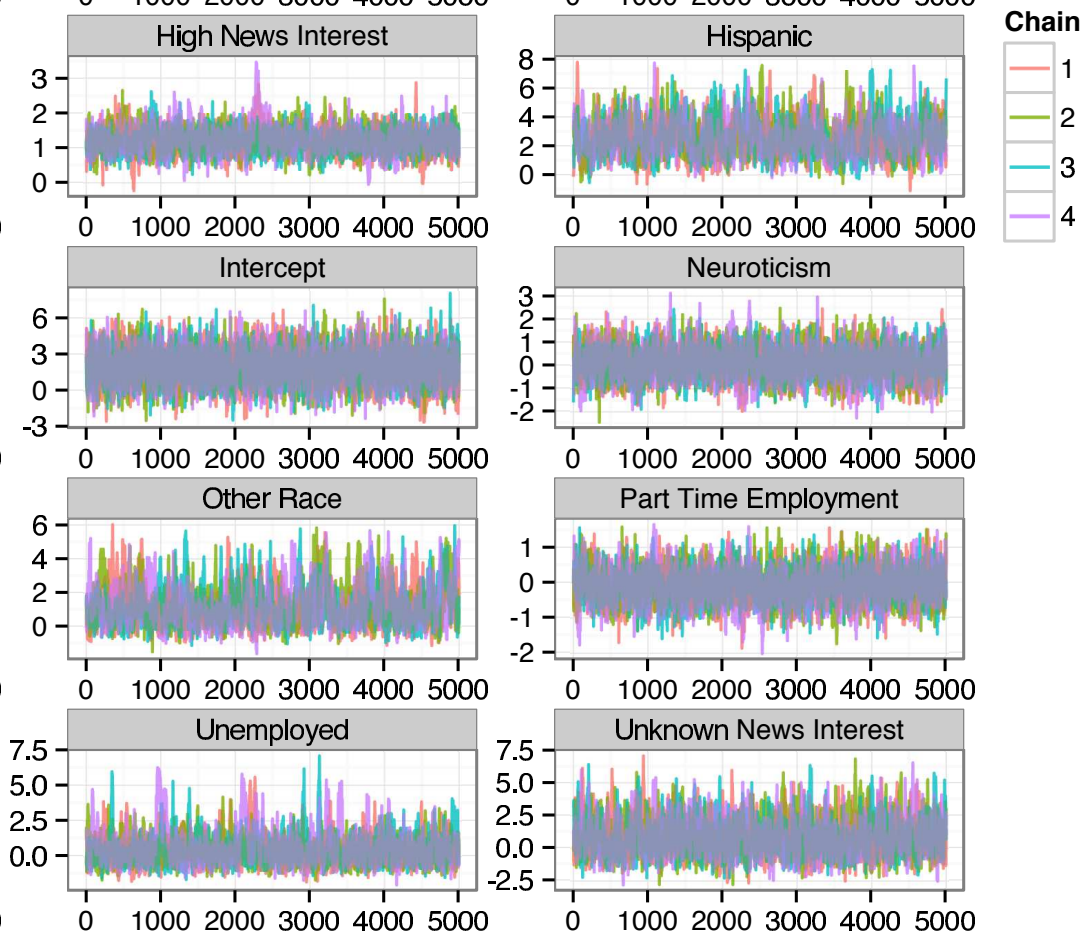

Iteration

Figure A-5: Traceplots of Decisiveness Coefficient Draws. 


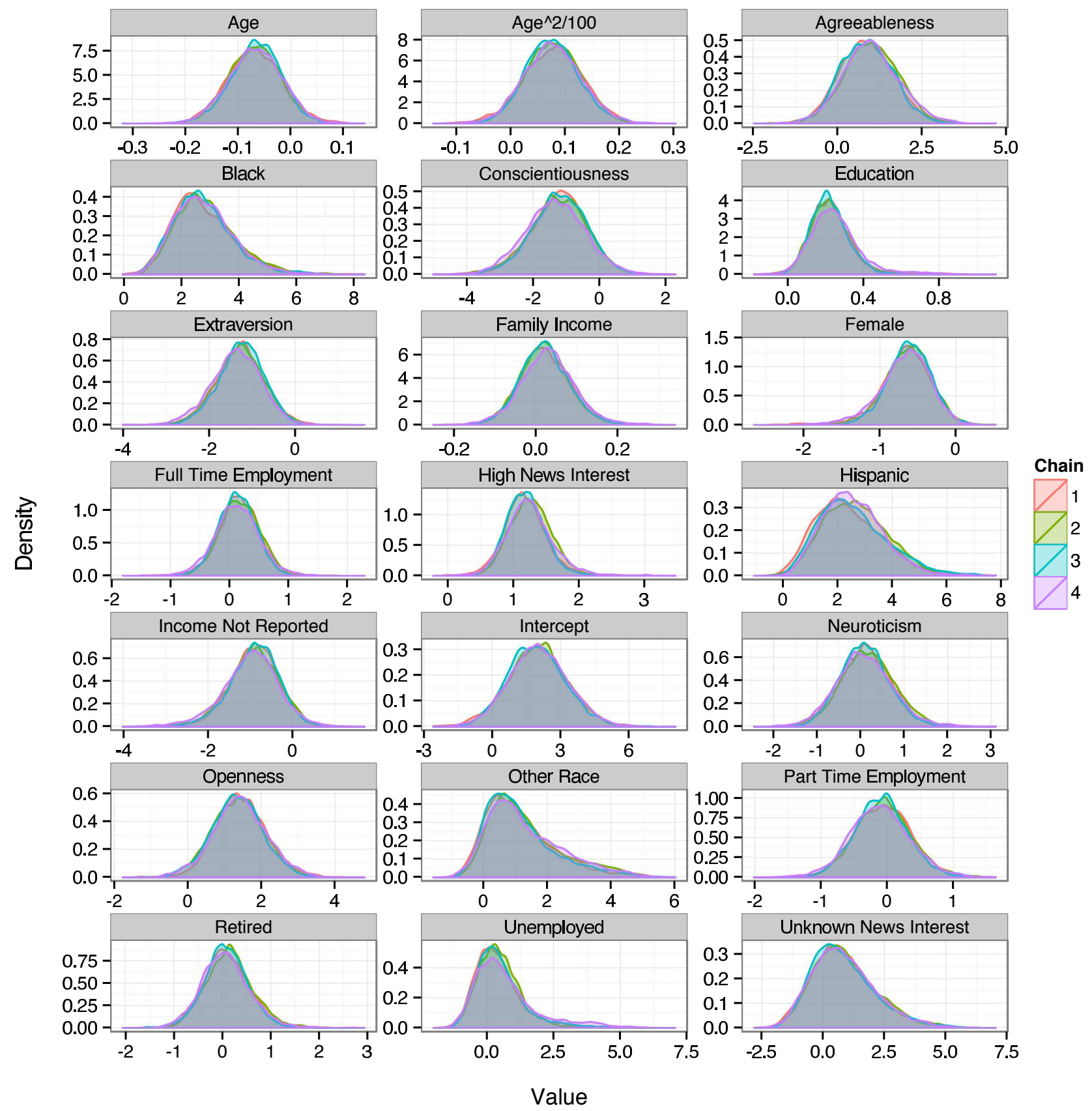

Figure A-6: Density Plot of Decisiveness Coefficient Draws. 

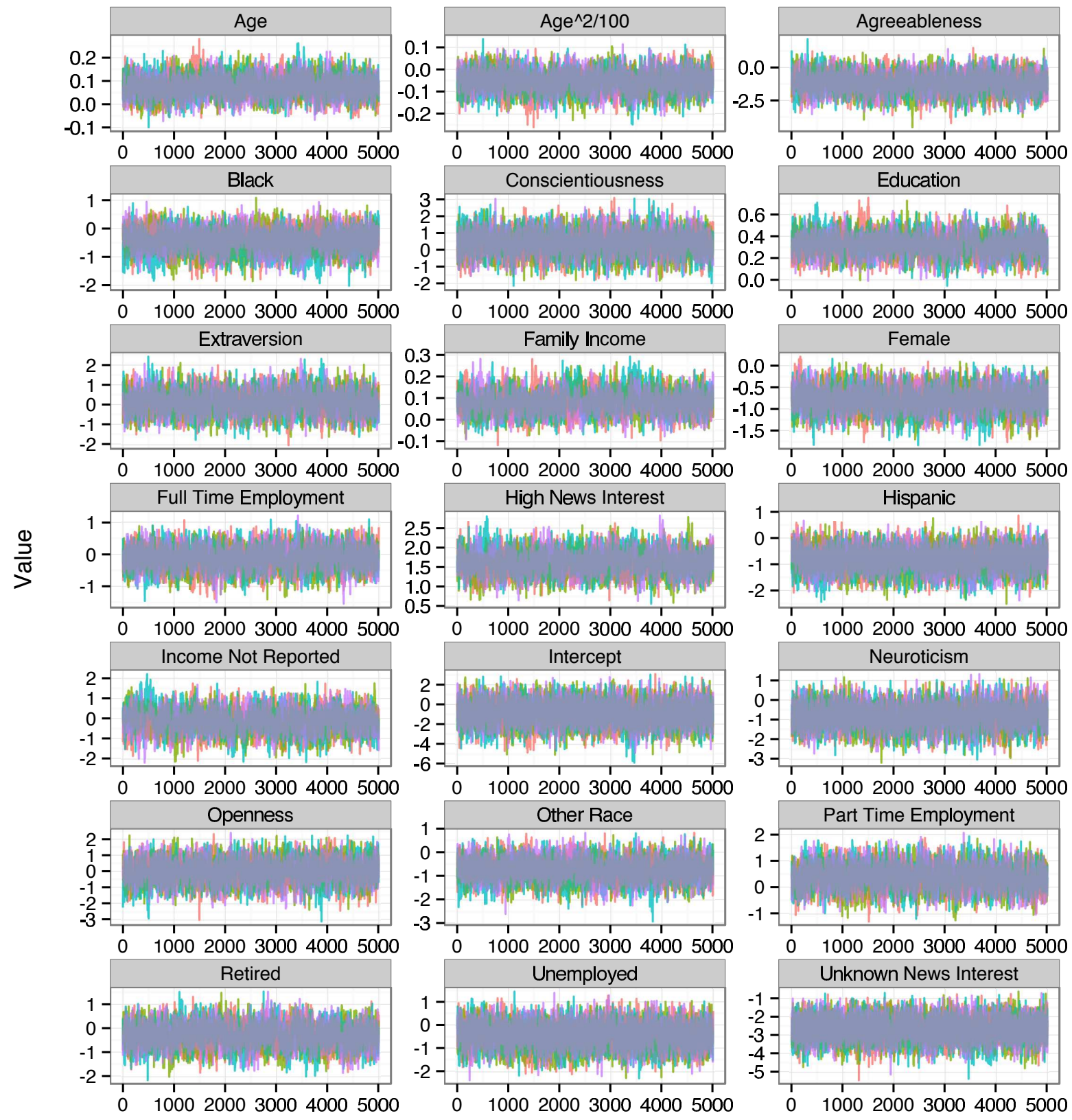

High News Interest
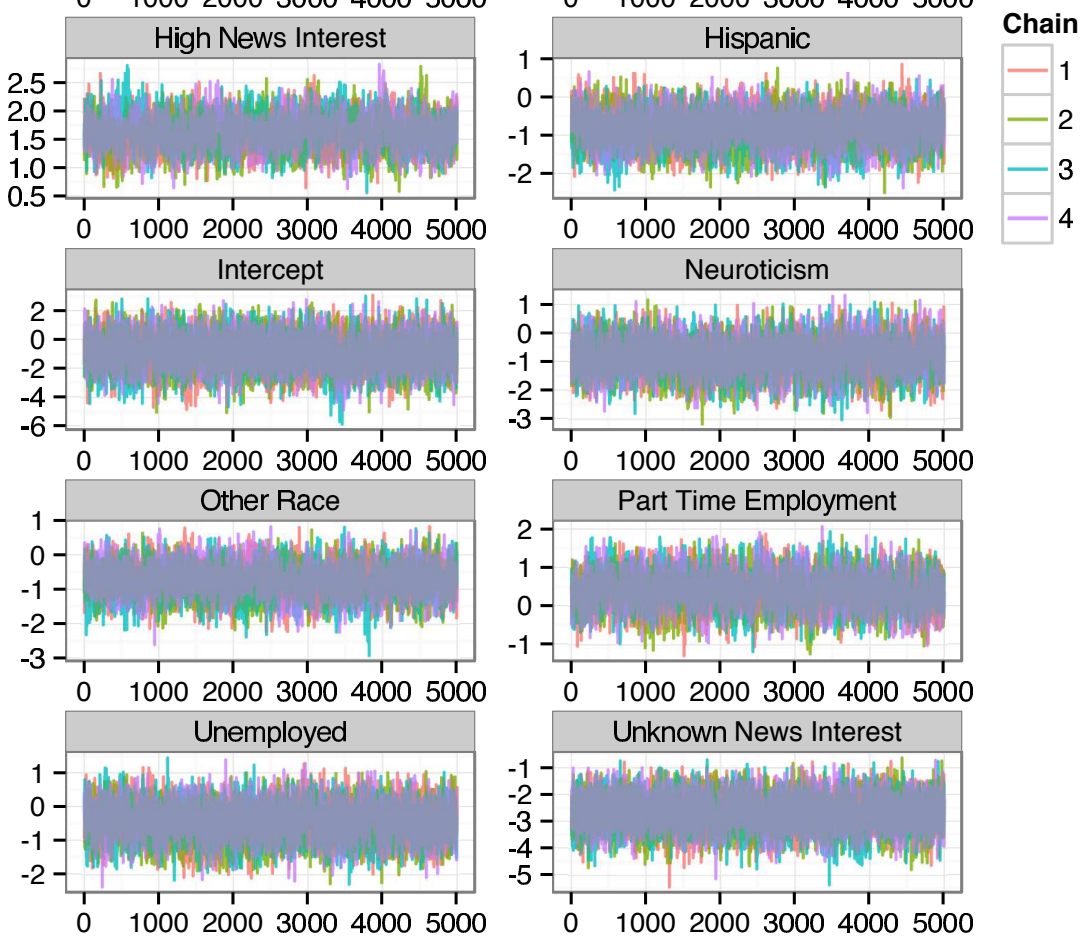

Iteration

Figure A-7: Traceplots of Saliency Intercept Coefficient Draws. 

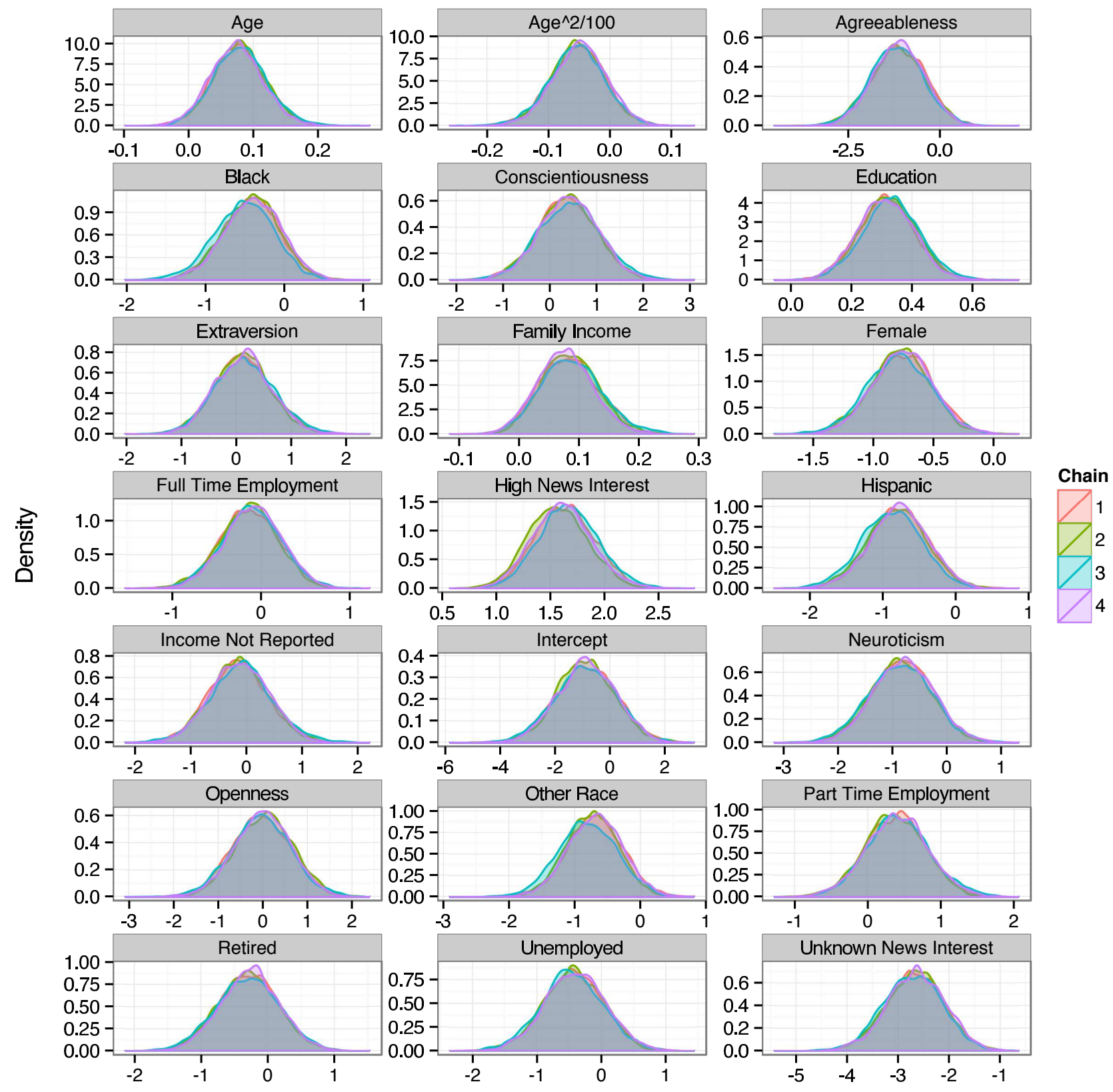

Value

Figure A-8: Density Plot of Saliency Intercept Coefficient Draws. 


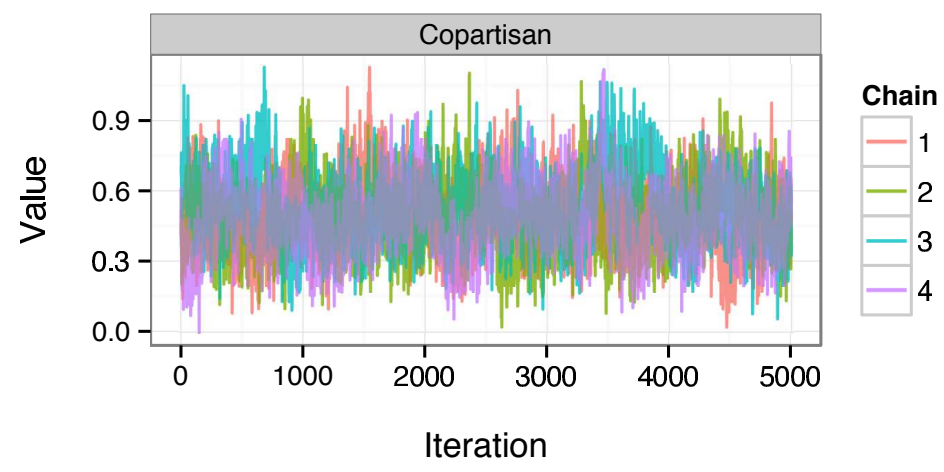

Figure A-9: Traceplot of Saliency Slope Coefficient Draws.

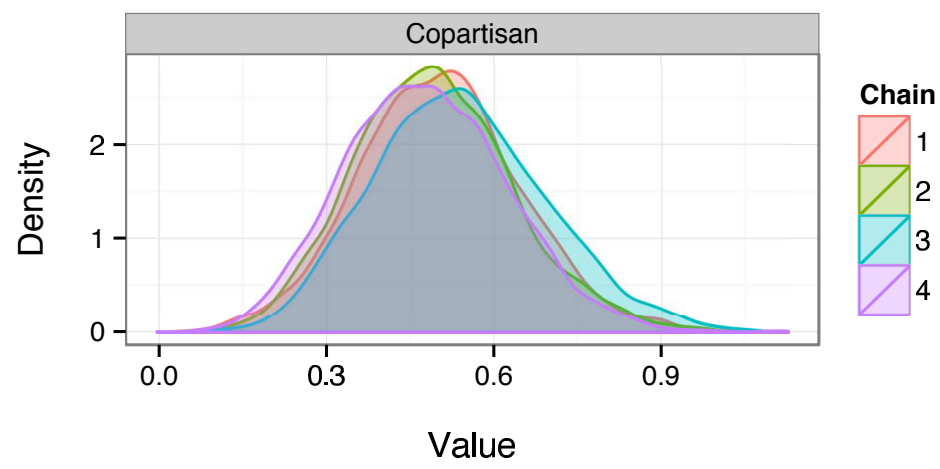

Figure A-10: Density Plot of Saliency Slope Coefficient Draws. 


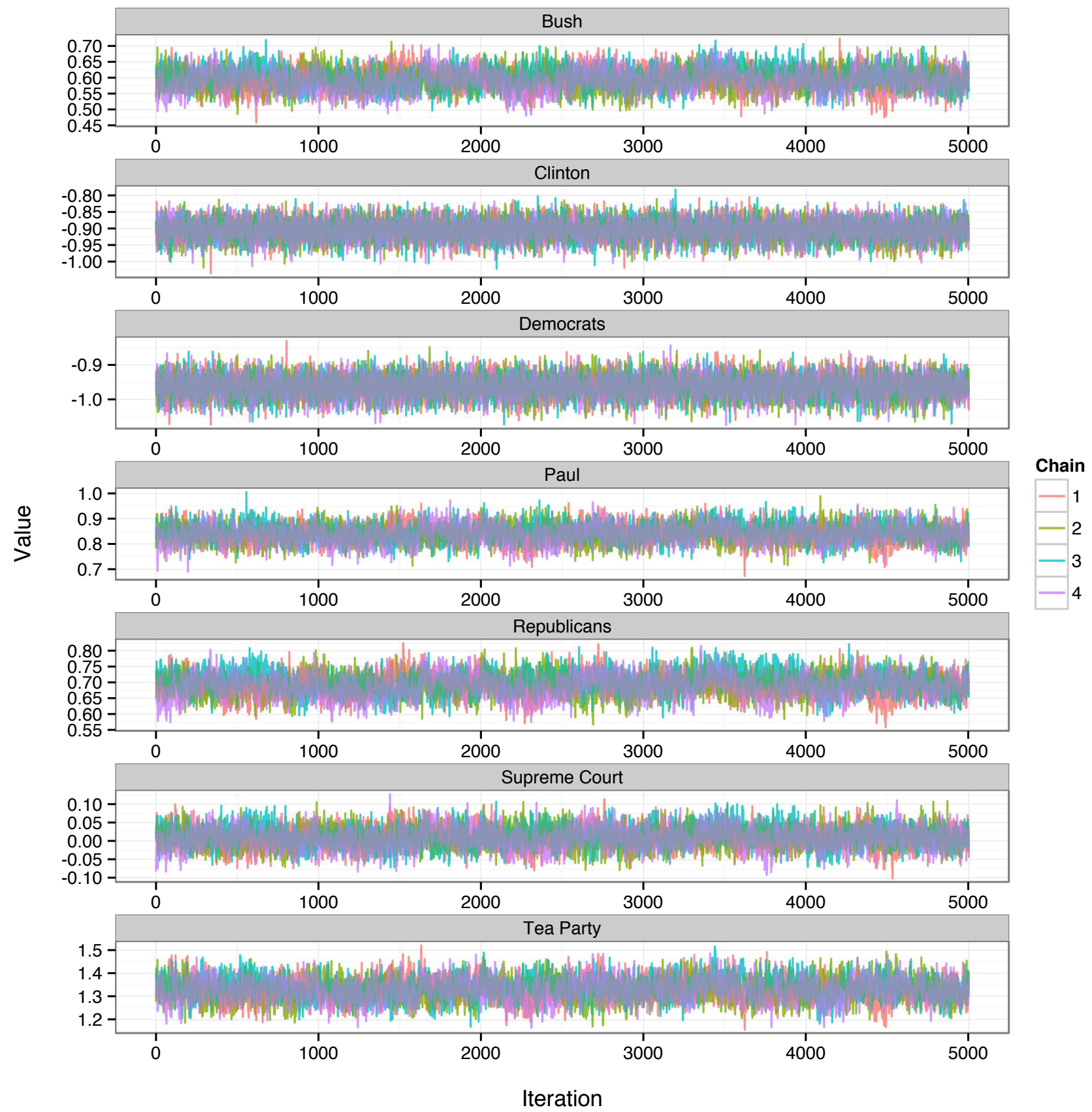

Figure A-11: Traceplots of Estimated Stimuli Placement Draws. 


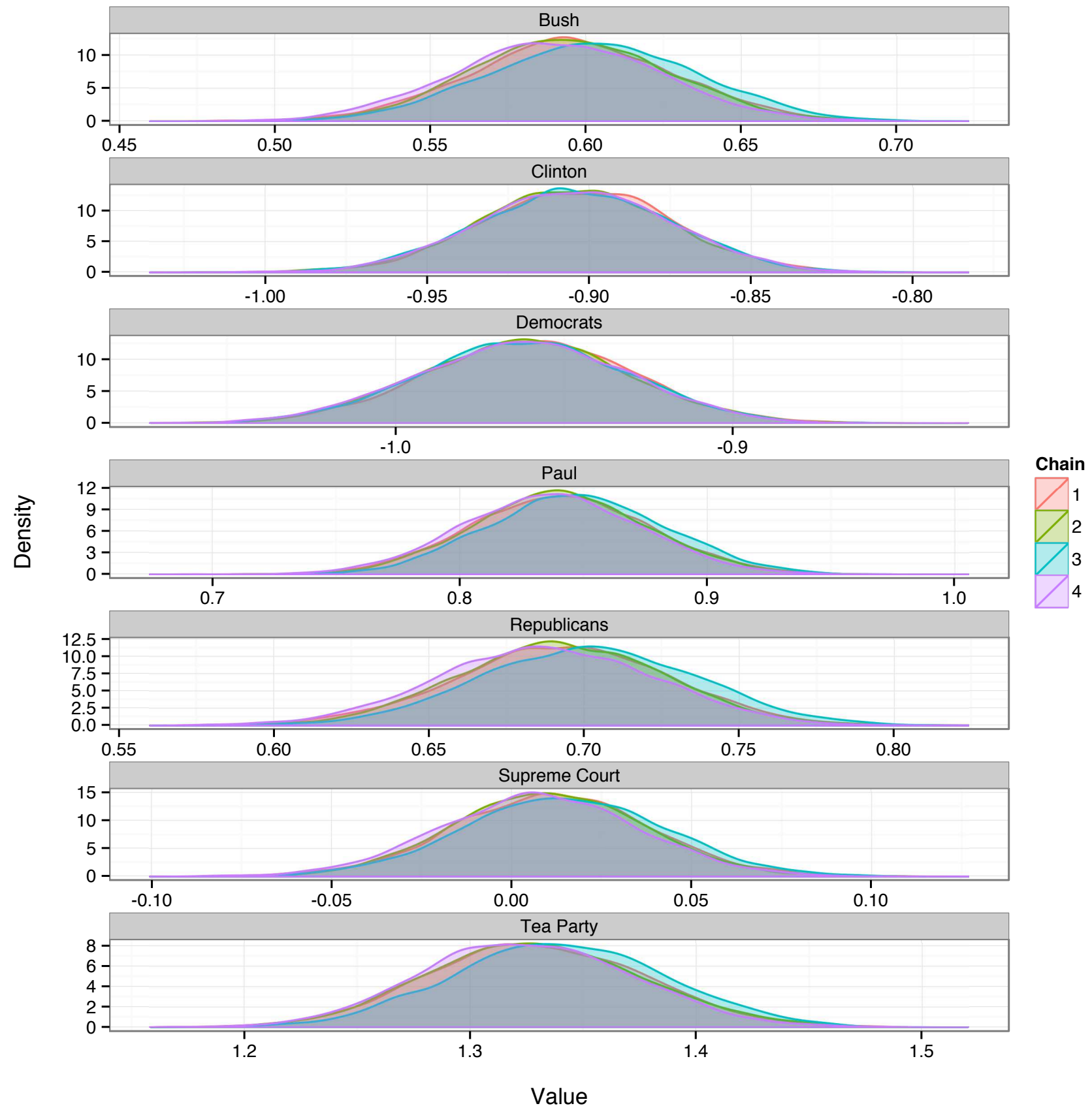

Figure A-12: Density Plots of Estimated Stimuli Placement Draws. 


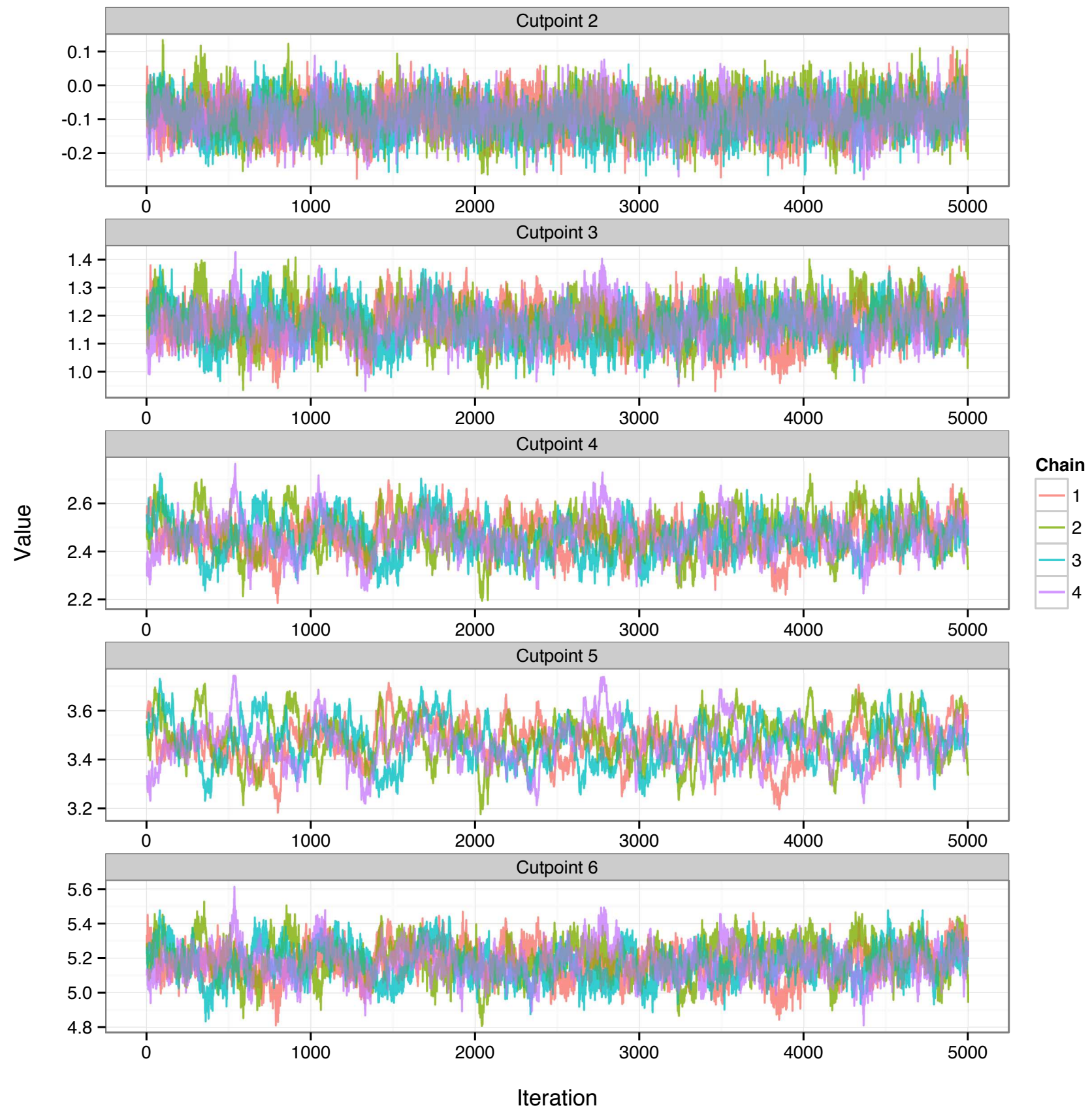

Figure A-13: Traceplots of Cutpoint Estimate Draws. 


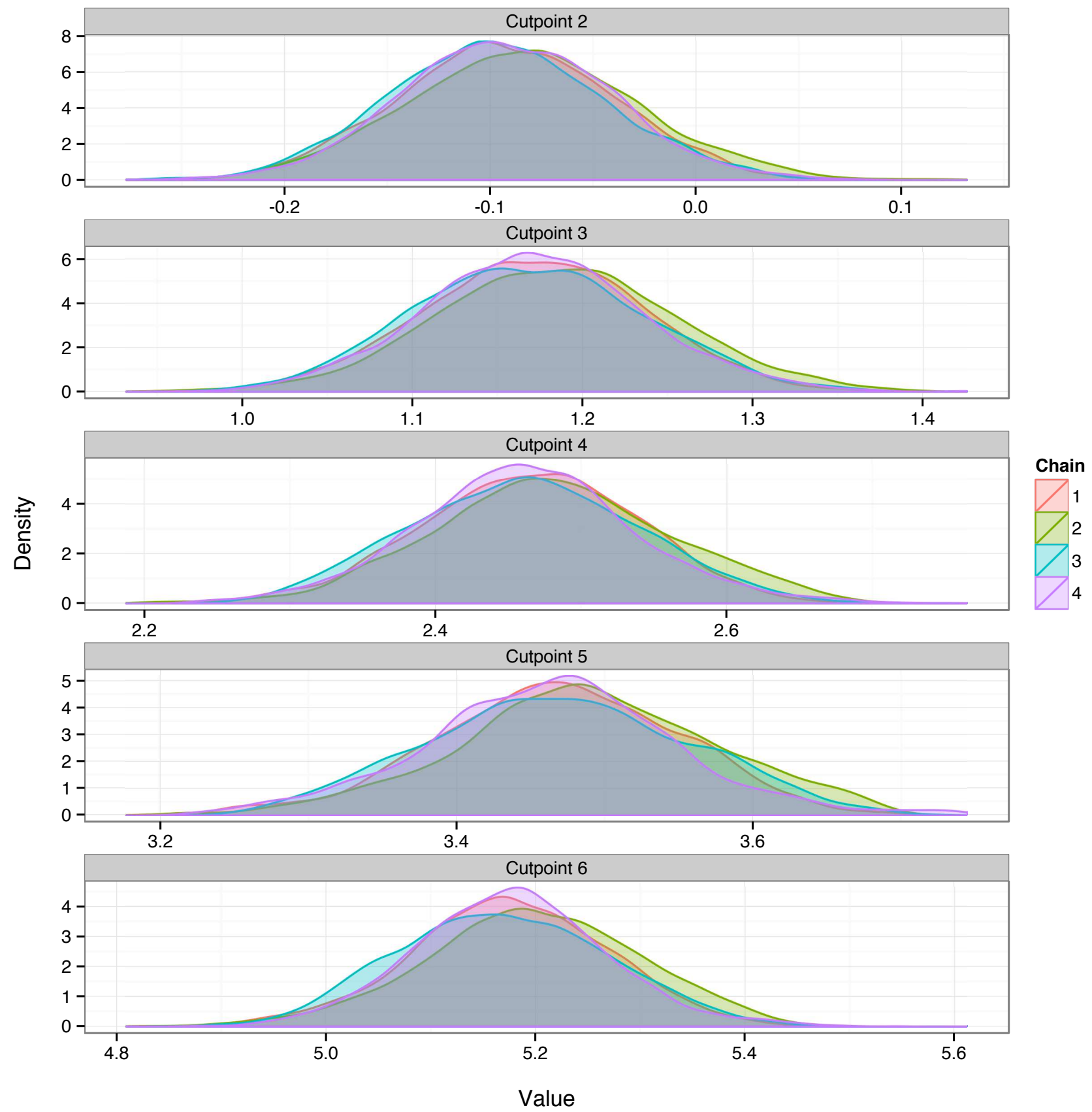

Figure A-14: Density Plots of Cutpoint Estimate Draws. 